\title{
O gênero Hypnea (Cystocloniaceae, Rhodophyta) no litoral do estado da Bahia, Brasil
}

\author{
Priscila Barreto de Jesus ${ }^{1,2 *}$, Alessandra Selbach Schnadelbach ${ }^{1,3}$ \& José Marcos de Castro Nunes ${ }^{1,2}$ \\ ${ }^{1}$ Programa de Pós-Graduação em Botânica, Departamento de Ciências Biológicas, Universidade Estadual de \\ Feira de Santana, Feira de Santana, Bahia, Brasil. \\ ${ }^{2}$ Laboratório de Algas Marinhas, Departamento de Botânica, e ${ }^{3}$ Laboratório de Genética e Evolução Vegetal, \\ Departamento de Biologia Geral. Instituto de Biologia, Universidade Federal da Bahia, Salvador, Bahia, Brasil.
}

\begin{abstract}
Resumo - É apresentado um estudo morfoanatômico detalhado do gênero Hypnea no estado da Bahia. Foram reconhecidas oito espécies: H. cenomyce, $H$. cervicornis, $H$. cornuta, $H$. musciformis, $H$. nigrescens, $H$. platyclada, $H$. spinella e $H$. valentiae. É apresentada uma chave de identificação, além de descrições, ilustrações, comparações com táxons relacionados e mapas de distribuição na Bahia para cada espécie. Palavras-chave adicionais: diversidade, Gigartinales, morfologia, Nordeste, taxonomia.
\end{abstract}

\begin{abstract}
The genus Hypnea (Cystocloniaceae, Rhodophyta) on the coast of Bahia, Brazil) - A detailed morpho-anatomical study of the genus Hypnea from the state of Bahia is presented. Eight species have been recognized: H. cenomyce, H. cervicornis, H. cornuta, H. musciformis, H. nigrescens, H. platyclada, H. spinella and $H$. valentiae. An identification key, as well as descriptions, illustrations, comparisons with related taxa and maps of distribution in Bahia for each species, are presented.

Additional keywords: diversity, Gigartinales, morphology, Northeast Brazil, taxonomy.
\end{abstract}

O gênero Hypnea J.V.Lamouroux foi estabelecido em 1813 com base em cinco espécies caracterizadas por apresentarem fronde cilíndrica e frutificação subulada, a maioria delas segregada do gênero Fucus Linnaeus (Tanaka 1941). Após os trabalhos de Lamouroux (1813), muitas espécies foram incluídas no gênero, porém o primeiro arranjo sistemático foi proposto por J. Agardh em 1852, que descreveu vinte espécies e as classificou em três seções com base no hábito do talo: Virgatae, Spinuligerae e Pulvinatae.

Segundo Collins \& Harvey (1917), nenhum gênero de algas vermelhas teria espécies tão pobremente definidas e com tão poucas características diacríticas quanto Hypnea. Masuda et al. (1997) listaram algumas características morfológicas potencialmente úteis para separar as espécies de Hypnea: sistema basal e hábito da alga; tamanho e textura do talo; cor das algas herborizadas e recém-coletadas; iridescência; eixo principal distinto; forma dos eixos principais em seção transversal; abundância de ramos laterais e proliferações; largura dos eixos e ramos; presença de ramos e râmulos especiais; direção da ramificação; frequência de espessamento lenticular na parede das células; presença de pequenas células ao redor da célula axial e posição dos soros tetrasporangiados nos râmulos férteis. Entretanto, um exame detalhado da literatura mostra que a maioria dos autores utiliza essencialmente as características de hábito e padrão de ramificação, presença ou ausência de gavinhas, disposição dos tetrasporângios nos soros e forma e

\footnotetext{
*Autor para correspondência: priscilla_b.j@hotmail.com

Editor responsável: Alessandro Rapini

Submetido: 9 abr. 2013; aceito: 28 jun. 2013

Publicação inicial: 26 jul. 2013; versão final: 2 maio 2014
}

arranjo dos râmulos para diferenciar as espécies de Hypnea; as demais são utilizadas eventualmente apenas. Schenkman (1986) relata que somados a esta dificuldade na identificação das espécies, a maioria dos autores não apresenta ilustrações das plantas estudadas e, como consequência, a morfologia externa e a anatomia das estruturas de reprodução das espécies são pouco conhecidas. Estes problemas persistem, sendo difícil estudar criticamente essas espécies por falta de literatura específica que abarque as características importantes para separá-las.

Atualmente, são referidas 67 espécies de Hypnea (Guiry \& Guiry 2013), amplamente distribuídas nos mares tropicais e subtropicais. Wynne (2011) reconhece para a costa tropical e subtropical da América nove espécies de Hypnea: H. cenomyce J.Agardh, $H$. cervicornis J.Agardh, $H$. cornuta (Kützing) J.Agardh, H. krugiana Hauck, H. musciformis (Wulfen) J.V.Lamouroux, $H$. nigrescens Grev. ex J.Agardh, $H$. spinella (C.Agardh) Kütz, H. valentiae (Turner) Mont. e H. volubilis Searles. Destas, apenas H. krugiana não foi citada para o Brasil. Por outro lado, a costa brasileira é a única área do Oceano Atlântico onde foram reconhecidos espécimes de Hypnea nigrescens (Guiry \& Guiry 2013). Dessa maneira, o litoral brasileiro pode ser considerado como região representativa para o gênero Hypnea na costa americana, contando com um total de oito espécies (Nunes et al. 2013). No litoral do Brasil, espécimes de Hypnea são frequentes na região entremarés, formando populações densas, crescendo fixas às rochas ou frequentemente como epífitas de outras algas. No entanto, trabalhos dedicados exclusivamente aos estudos das espécies deste gênero ainda são escassos; a 
maioria das informações é proveniente de levantamentos de floras regionais e listagens de espécies. Nunes (2005) referiu seis espécies de Hypnea para o litoral do estado da Bahia: $H$. cenomyce, $H$. musciformis, $H$. nigrescens, $H$. spinella, $H$. valentiae e Hypnea sp. (talo achatado). Recentemente, Jesus \& Nunes (2012) fizeram a primeira referência de $H$. cornuta para o Estado e Jesus et al. (2013) descreveram uma nova espécie de Hypnea de talo achatado com base em material coletado por Nunes (2005) na Bahia: H. platyclada P.B.Jesus \& J.M.C.Nunes.

Embora algumas espécies de Hypnea estejam incluídas em praticamente todas as floras regionais do Brasil, faltam estudos taxonômicos detalhados e atualizados para a maioria delas. Não existem análises acuradas dos caracteres morfológicos e anatômicos comumente utilizados para a delimitação de suas espécies, o que resulta em inúmeras identificações errôneas no litoral brasileiro. Assim, este trabalho teve por objetivo realizar um estudo taxonômico detalhado de Hypnea, contribuindo para o conhecimento da diversidade da flora do litoral do estado da Bahia, bem como do litoral brasileiro.

\section{MATERIAL E MÉTODOS}

O estado da Bahia possui o litoral mais extenso do país, com $1.103 \mathrm{~km}$. Foram demarcados 15 pontos de coleta distribuídos ao longo do litoral baiano, abrangendo quatro macrorregiões econômicas: Litoral Norte, Região Metropolitana de Salvador, Litoral Sul e Extremo Sul. Os espécimes foram coletados entre os anos de 2010 e 2011.

Os exemplares foram coletados seletivamente na região entremarés durante as marés baixas de sizígia. $\mathrm{O}$ material coletado foi acondicionado em sacos plásticos devidamente etiquetados e levado ao laboratório, onde as amostras foram triadas, fixadas em formol a $4 \% \mathrm{em}$ água do mar, e mantidas em frascos plásticos para posterior observação e descrição de características vegetativas e reprodutivas.

Para cada espécime estudado, medidas mínimas e máximas foram obtidas a partir de um conjunto de 10 medições para cada estrutura analisada, através de ocular micrométrica em microscópio óptico (Ward's). As medidas das estruturas foram tomadas considerando-se seu maior eixo. Para observação da estrutura interna, foram realizados cortes à mão livre com auxílio de lâmina de aço em três regiões do talo: base, região mediana e ápice. Para a descrição das espécies, foram utilizados os dados dos cortes realizados na porção basal do talo, onde as variações de tamanho e forma das células são menores. Os cortes foram corados com solução aquosa de azul de anilina a $5 \%$ para evidenciar conexões celulares, estruturas de reprodução e espessamentos lenticulares. Posteriormente, os cortes foram observados ao microscópio óptico.

A documentação das características foi realizada através de fotomicrografias obtidas com o auxílio de programa de captura de imagem (QCapture Pro) e câmera digital (QImaging GO-3) acoplada ao fotomicroscópio (Olympus ${ }^{\circledR}$ trinocular CX31RTS5). Após realização das observações, os exemplares foram herborizados de acordo com Nunes (2010) e registrados no Herbário Alexandre Leal Costa (ALCB) do Instituto de Biologia da Universidade Federal da Bahia. Para fins comparativos, foram examinados materiais-tipo procedentes dos Herbários E (Royal Botanic Garden Edinburgh - Escócia) e DUKE (Universidade de Duke da Carolina do Norte - Estados Unidos), além de exemplares dos principais herbários brasileiros (HUEFS, RFA, RB, SPF e SP). Espécimes masculinos, femininos e tetraspóricos foram simbolizados por $\hat{\sigma}$, + e $\varnothing$, respectivamente; exemplares estéreis não foram simbolizados.

\section{Tratamento TaxonôMico}

\section{Hypnea J.V.Lamouroux}

Talo epifítico ou epilítico, ereto ou prostrado, textura membranácea a cartilaginosa e coloração variando entre amarelada, esverdeada, rósea, vinácea, ou amarronzada. Fixo ao substrato através de discos de fixação, gavinhas, ramos rizoidais ou estolão. Eixo principal evidente ou não, cilíndrico ou achatado, cujo diâmetro geralmente permanece homogêneo em todo o talo afilando-se em direção ao ápice. Ápice reto e agudo, por vezes bifurcado, recurvado ou em forma de gavinha terminando em uma nítida célula apical. Ramos laterais cilíndricos ou achatados inseridos de maneira alterna a irregular em vários planos. Râmulos curtos espinescentes dispostos por todo o talo. Organização uniaxial e estrutura pseudoparenquimatosa. Célula axial pigmentada de tamanho menor, igual ou maior que as periaxiais hialinas; células medulares hialinas, gradualmente menores em direção à periferia; células corticais pigmentadas. Espessamentos lenticulares nas paredes das células periaxiais ou medulares. Tetrasporângios zonados, circundando e provocando alargamento da região cortical da base, meio ou ápice dos râmulos. Cistocarpos globosos sem ostíolo evidente, solitários ou em grupos, produzidos nos ramos e râmulos laterais; carposporângios piriformes, dispersos no interior do cistocarpo. Espermatângios esféricos, formados em cadeia na região cortical circundando a base ou meio dos râmulos. 


\section{Chave de identificação}

1. Talo achatado 6. H. platyclada

1'. Talo cilíndrico.

2. Plantas formando pequenos tufos até $1 \mathrm{~cm}$ alt., ramos delgados até $160 \mu \mathrm{m}$ diâm., 1 camada de células medulares, tetrasporângios imersos na região medular ocupando praticamente metade do diâmetro do talo ..

2'. Plantas > 2 cm alt., ramos > $300 \mu \mathrm{m}$ diâm., 2 ou 3 camadas de células medulares, tetrasporângios formados na região cortical dos râmulos.

3. Talo com porções prostradas fortemente emaranhadas.

4. Talo formando tufos densos tipo almofada, com muitas anastomoses, soros tetrasporangiados geralmente formados no ápice dos râmulos

4'. Talo com eixos eretos partindo da porção prostrada, anastomoses ausentes, soros tetrasporangiados formados na região basal e mediana dos râmulos 5. H. nigrescens

3'. Talo com porções prostradas não emaranhadas ou completamente ereto.

5. Cutícula mucilaginosa espessa, presença de propágulos estrelados

3. H. cornuta

5'. Cutícula mucilaginosa delgada, ausência de propágulos estrelados.

6. Eixo principal e ramos com ápices em forma de gavinhas espessas, porções basais com râmulos dispostos em ângulo reto, aspecto emaranhado 4. H. musciformis

6'. Eixo principal e ramos com ápices agudos ou recurvados, mas nunca inflados, râmulos dispostos em ângulo agudo em volta de todo o talo, aspecto frouxo.

7. Ápices bifurcados, em forma de galhada de cervo, ramos formando ângulos de $50-80^{\circ} \mathrm{com}$ o eixo principal, râmulos apicais dispostos de maneira alterna a dística ..... 2. H. cervicornis

7'. Ápices retos, ramos formando ângulos retos com o eixo principal e râmulos apicais dispostos de maneira alterna a espiralada 8. H. valentiae

1. Hypnea cenomyce J.Agardh, Sp. Alg. 2(2): 452. 1852.

Figuras 1 e 2.

Talo com porções prostradas e eretas, membranáceo, coloração róseo-avermelhada a amarronzada, formando pequenos tufos de $0,5-1 \mathrm{~cm}$ alt. Fixo ao substrato através de vários discos de fixação originados nos ramos e na porção estolonífera fracamente emaranhada, $0,3-0,5 \mathrm{~cm}$ compr., de onde partem ramos eretos. Ramos eretos, 83-159 $\mu$ m diâm., cilíndricos, pouco ramificados, inseridos perpendicularmente na porção estolonífera com até 4 $\mathrm{mm}$ alt. Anastomoses ausentes. Ápice agudo, 19-40 $\mu \mathrm{m}$ diâm. Râmulos esparsos, 136-934 $\mu \mathrm{m}$ compr., inseridos de maneira irregular em vários planos, mas sempre em ângulos retos. Célula axial de parede espessa, 16-21 $\mu \mathrm{m}$ diâm.; 5 ou 6 periaxiais ovais, 34-51 $\mu \mathrm{m}$ diâm.; uma camada de células medulares e de células corticais, 6-10 $\mu \mathrm{m}$ diâm. Espessamentos lenticulares nas células periaxiais. Tetrasporângios 55-78 $\mu \mathrm{m}$ compr. $\times$ 29-44 $\mu \mathrm{m}$ diâm., geralmente ocupando grande parte da região medular dos ramos e produzindo alargamento característico desta porção. Exemplares gametofíticos não encontrados.

No litoral brasileiro, Hypnea cenomyce é registrada apenas para os estados da Bahia, Espírito Santo e Rio de Janeiro (Yoneshigue-Valentin 1985; Amado-Filho 1991; Nunes 2005; Guimarães 2006; YoneshigueValentin et al. 2008; Nunes et al. 2013). E/F9: rara, mediolitoral, epilítica ou epífita na região frontal do recife. Coletada atirada à praia ou crescendo sobre Peyssonnelia sp. Associada a Centroceras clavulatum (C.Agardh) Montagne, Cladophora sp., Herposiphonia secunda (C.Agardh) Ambronn e Spyridia hypnoides (Bory de Saint-Vincent) Papenfuss.

Material selecionado - Lauro de Freitas, Villas do Atlântico, 7 nov. 2002, J.M. C. Nunes et al. (ALCB 53376-Ø); Salvador, Stella Maris, 17 abr. 2000, J.M. C. Nunes (ALCB 53348), Farol da Barra, 16 jul. 2007, L.F. Gomes (HUEFS 148400), 23 out. 2007, L.F. Gomes (HUEFS 148423).

Material adicional examinado - BRAZIL. RIO DE JANEIRO: Cabo Frio, Praia do Farol, 5 fev. 1983, Y. YoneshigueValentin (SPF 51066, RFA 4007, 4008); Saquarema, Praia da Vila, 12 jun. 1986, G. Amado-Filho et al. (RB 382494-Ø).

Os exemplares analisados se diferenciam das demais espécies de Hypnea no litoral baiano pelas pequenas dimensões do talo, ramos delgados e disposição dos tetrasporângios nos ramos férteis (Tabela 1). O padrão anatômico visto em corte transversal, bem como a presença de inúmeros discos de fixação em todas as porções do talo, constituem outras peculiaridades desta espécie. Estas características concordam com as descrições e ilustrações fornecidas por Yoneshigue-Valentin (1985) e Amado-Filho (1991) para o material do Rio de Janeiro e por Nunes (2005) para o litoral baiano.

De Toni (1897) e Lawson \& John (1987) descreveram Hypnea cenomyce apresentando ápices obtusos. Tanaka (1941) relata que os espécimes de H. cenomyce do Japão podem apresentar tanto ápices agudos e espinescentes quanto discoides; o mesmo foi documentado por Chiang (1997) para esta espécie em Taiwan. Ogawa \& Lewmanomont (1981), AmadoFilho (1991) e Prud'homme van Reine \& Trono Jr (2001) ressaltam a presença de eixos cilíndricos com delgados ramos espinescentes. Assim como observado 

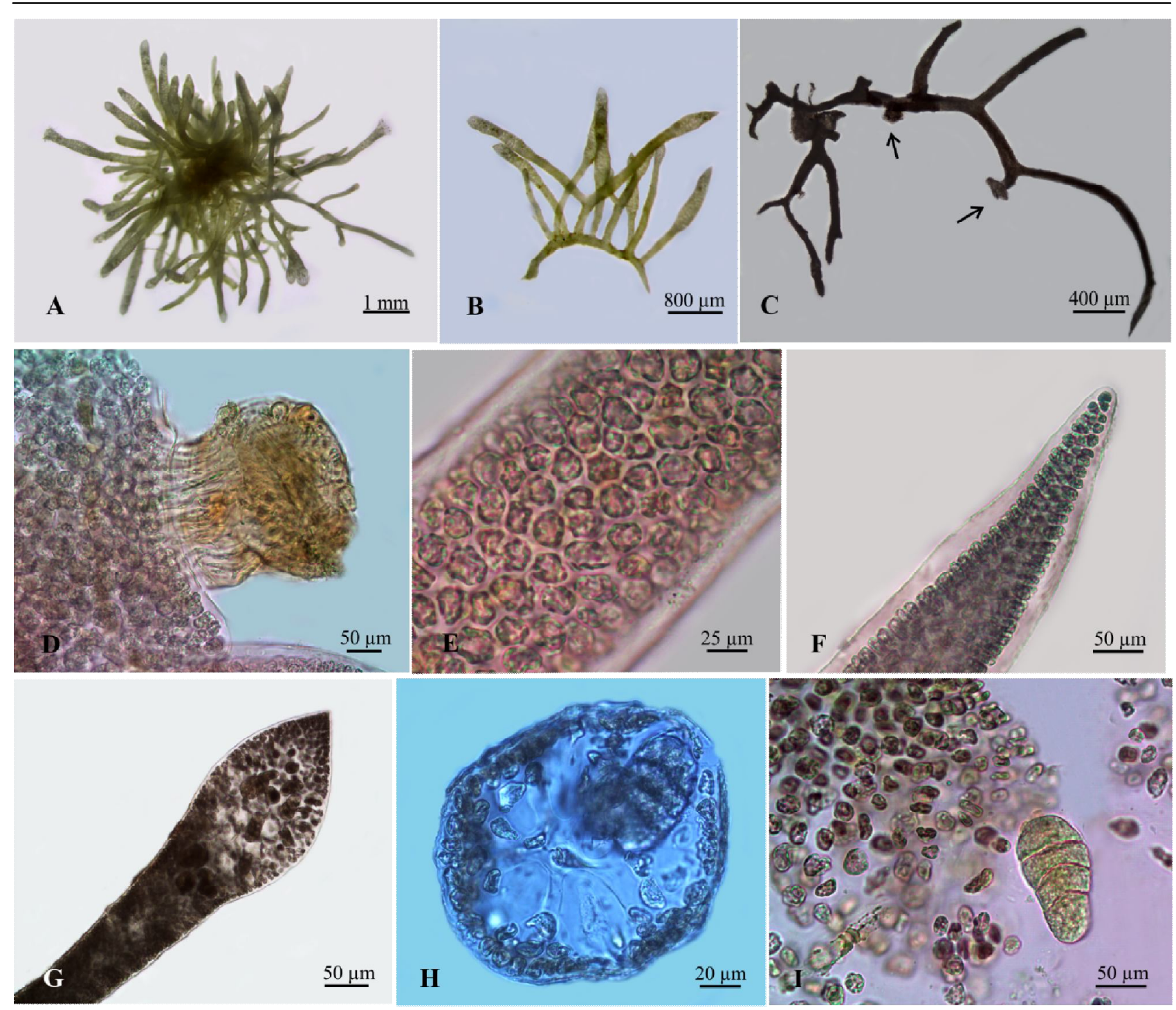

Figura 1. Hypnea cenomyce (ALCB 53376, 53348): A- hábito de um exemplar tetrasporofítico; B- porção estolonífera de onde partem ramos eretos; C- detalhe de porção estolonífera com discos de fixação (setas); D- detalhe de um disco de fixação; E- células corticais em vista superficial; F- região apical de um ramo evidenciando uma distinta célula apical; G- tetrasporângios desenvolvidos na porção apical de um ramo produzindo alargamento desta região; H- corte transversal de um râmulo fértil evidenciando os espessamentos lenticulares nas células periaxiais e um tetrasporângio zonado; I- tetrasporângio zonado em detalhe.

por Yoneshigue-Valentin (1985) e Amado-Filho (1991) para os espécimes do Rio de Janeiro, os exemplares encontrados no litoral do estado da Bahia apresentam ápices geralmente agudos (Figura 1F). Entretanto, o desenvolvimento de soros tetrasporangiados na região apical dos râmulos férteis pode lhes conferir uma aparência arredondada (Figura $1 \mathrm{G})$.

2. Hypnea cervicornis J.Agardh, Sp. Alg. 2 (2): 451. 1852.

Figuras 3 e 4.

Talo ereto, textura membranácea a cartilaginosa, coloração amarela, róseo-esverdeada ou amarronzada, 4-12(-24) cm alt. Fixo ao substrato através de disco de fixação primário ou ramos rizoidais recurvados com discos de fixação acessórios. Eixos principais cilíndricos e evidentes, 529-1.036 m diâm. Ramos inseridos acima de $1 \mathrm{~cm}$ da base, 2-8,5 cm compr.; ramificação dicotômica a subdicotômica em ângulos abertos. Anastomoses raras entre os ramos. Ápice reto, bifurcado, 264-535 $\mu \mathrm{m}$ diâm. Râmulos dispostos irregularmente nas regiões basal e mediana, e de maneira alterna com tendência a dística nas regiões próximas ao ápice. Pêlos hialinos em toda a superfície do talo. Célula axial pequena, 27-61 $\mu \mathrm{m}$ diâm.; periaxiais 4-6, oval-triangular, geralmente de mesmo tamanho (175-321 $\mu \mathrm{m}$ diâm.) ou apresentando apenas uma delas de tamanho similar ao da célula axial (52-64 $\mu \mathrm{m}$ diâm.); 1 ou 2 camadas de células medulares arredondadas de tamanho variável (69-254 $\mu \mathrm{m}$ diâm.), 1 ou 2 camadas de células corticais, 5-9,8 $\mu \mathrm{m}$ diâm. Espessamentos lenticulares nas células periaxiais e/ou medulares em todas as porções do talo. Tetrasporângios $128-173 \mu \mathrm{m}$ compr. $\times$ 53-73 $\mu \mathrm{m}$ diâm., inseridos na porção basal e 


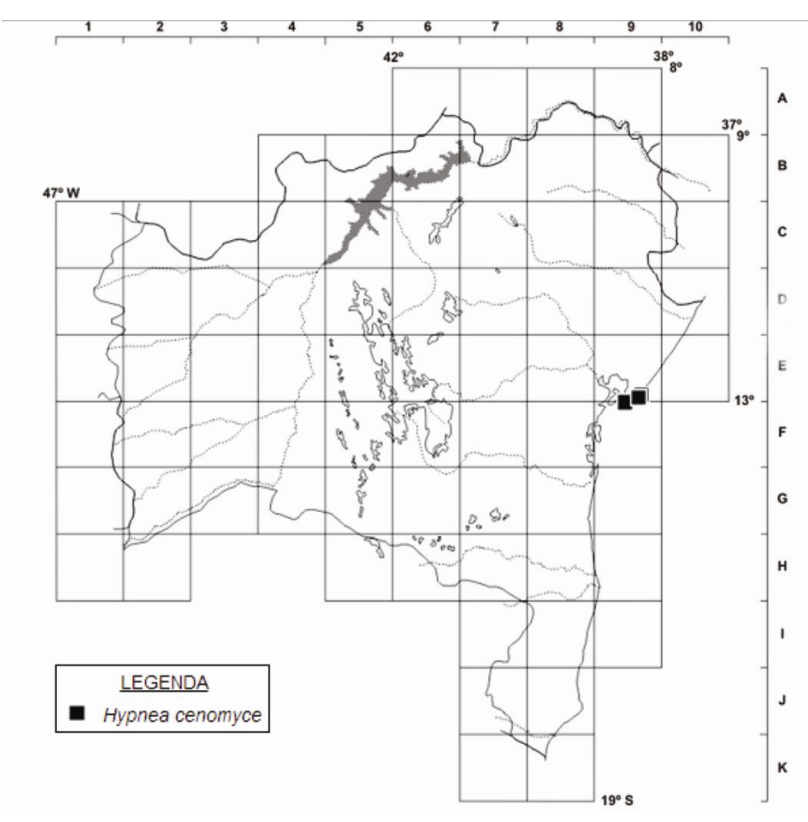

Figura 2. Mapa de distribuição de Hypnea cenomyce no litoral do estado da Bahia.

mediana dos râmulos (414-1.519 $\mu \mathrm{m}$ diâm.). Cistocarpos 495 de $771 \mu \mathrm{m}$ compr. $\times 549$ de $774 \mu \mathrm{m}$ alt., base sem constrição, com muitos espessamentos, 2-4 camadas de células arredondadas no pericarpo; carposporângios 18,5-27 $\mu \mathrm{m}$ diâm. Espermatângios 1,9-4,5 $\mu \mathrm{m}$ diâm., formados na base dos râmulos (692-1.153 $\mu$ m diâm.).

Espécie comum no Brasil, ocorrendo em praticamente todo o litoral (Nunes et al. 2013). E9/10, E/F9, I8/9: no mediolitoral, epilítica ou epífita na região protegida do recife, em poças ou em lagunas recifais, raramente agregadas. Crescendo sobre Acanthophora spicifera (M.Vahl) Børgesen, Bryothamnion triquetrum (S.G.Gmelin) M.A.Howe, Canistrocarpus cervicornis (Kützing) De Paula \& De Clerck, Chondracanthus acicularis (Roth) Fredericq, Digenea simplex (Wulfen) C.Agardh, Dictyopteris delicatula J.V.Lamouroux, Gelidiella acerosa (Forsskål) Feldmann \& G.Hamel, Gracilaria spp., Palisada perforata (Bory de Saint-Vincent), Sargassum sp. e coralináceas incrustantes. Associada a Cladophora vagabunda (Linnaeus) Hoek, Dictyopteris sp., Dictyota sp., Hypnea musciformis e Spyridia filamentosa (Wulfen) Harvey. Epifitada por Calotrix sp., Cladophora vagabunda, Centroceras clavulatum e Ceramium sp.

Material selecionado - Entre Rios, Subaúma, 25 out. 2010, P.B. Jesus et al. (ALCB 100224-Ø); Mata de São João, Praia do Forte, 25 set. 2010, P.B. Jesus et al. (ALCB 100217-Ø); Ilha de Itaparica, Vera Cruz, Mar Grande, 4 dez. 2010, P.B. Jesus et al. (ALCB 100219-Ø, ALCB 100223), Penha, 5 dez. 2010, P.B. Jesus et al. (ALCB 100218); Santa Cruz de Cabrália, Coroa Vermelha, 8 nov. 2010, P.B. Jesus et al. (ALCB 100200-Ø, 100221-ð̋); Porto Seguro, Arraial D'Ajuda, Mucugê, 7 nov. 2010, P.B. Jesus et al (ALCB 100222-ㅇ)
Hypnea cervicornis se distingue das demais espécies de Hypnea pelos últimos ramos dicotomicamente ramificados, atribuindo-lhe aspecto de galhada de cervo, característica que lhe confere o epíteto específico. Os exemplares cistocárpicos exibem aparência mais robusta devido à formação de muitos cistocarpos ao longo do talo, podendo inclusive, apresentar descaracterização do padrão de inserção dos râmulos nas regiões apicais. A análise conjunta de características como hábito, modo de inserção dos ramos no eixo principal, fixação ao substrato e forma do talo em corte transversal (Tabela I) foi essencial para a atribuição destes exemplares a H. cervicornis.

Lawson \& John (1987) comentaram sobre toda a confusão taxonômica, nomenclatural e biológica relacionada à distinção entre Hypnea cervicornis e $H$. spinella. Haroun \& Prud'Home van Reine (1993), estudando a biogeografia dos gêneros Laurencia J.V.Lamouroux e Hypnea no Arquipélago Macaronesiano, África, demonstraram que havia uma transição da forma típica de $H$. cervicornis para a forma típica de $H$. spinella. Os autores sugeriram que H. spinella seria somente uma forma de crescimento compacta, de hábitat com intensa ação das ondas, enquanto $H$. cervicornis seria uma forma de crescimento mais alongada, de hábitat com menor ação das ondas. Os autores propuseram então a sinoninimização desses táxons sob o nome $H$. spinella (C.Agardh) J.Agardh.

Schenkman (1986) e Lucio (2006) analisaram os tipos de Hypnea cervornis (LD 85/80-2825 - Agardh Herbarium 33878) e $H$. spinella (LD 85/80-2826 Agardh Herbarium 33888). Schenkman (1986) afirmou que a análise dos tipos não é muito esclarecedora, pois geralmente encontram-se mal preservados e não trazem informações sobre o local de coleta e/ou coletor. Dessa maneira, a autora decidiu manter a identificação que vinha sendo adotada pelos autores contemporâneos, principalmente os brasileiros, separando as duas espécies. Lucio (2006), entretanto, apresentou detalhes anatômicos similares para os dois exemplares-tipo e resolveu, apesar das diferenças de hábito e forma do eixo principal, considerar estas duas espécies como coespecíficas.

De fato, Hypnea cervicornis e $H$. spinella assemelham-se no que diz respeito à estrutura interna, ambas apresentando uma pequena célula axial geralmente rodeada por cinco ou seis periaxiais grandes e uma a duas camadas de células corticais pigmentadas (Tabela 1; Figura $3 \mathrm{E}=H$. cervicornis; Figura $13 \mathrm{D}=H$. spinella . De acordo com Masuda et al. (1997), a forma e disposição das células em corte transversal do eixo principal possui importante valor taxonômico. Entretanto, não apenas esta, mas todas as características, morfológicas e anatômicas, devem ser analisadas conjuntamente para a identificação inequívoca dessas espécies. 


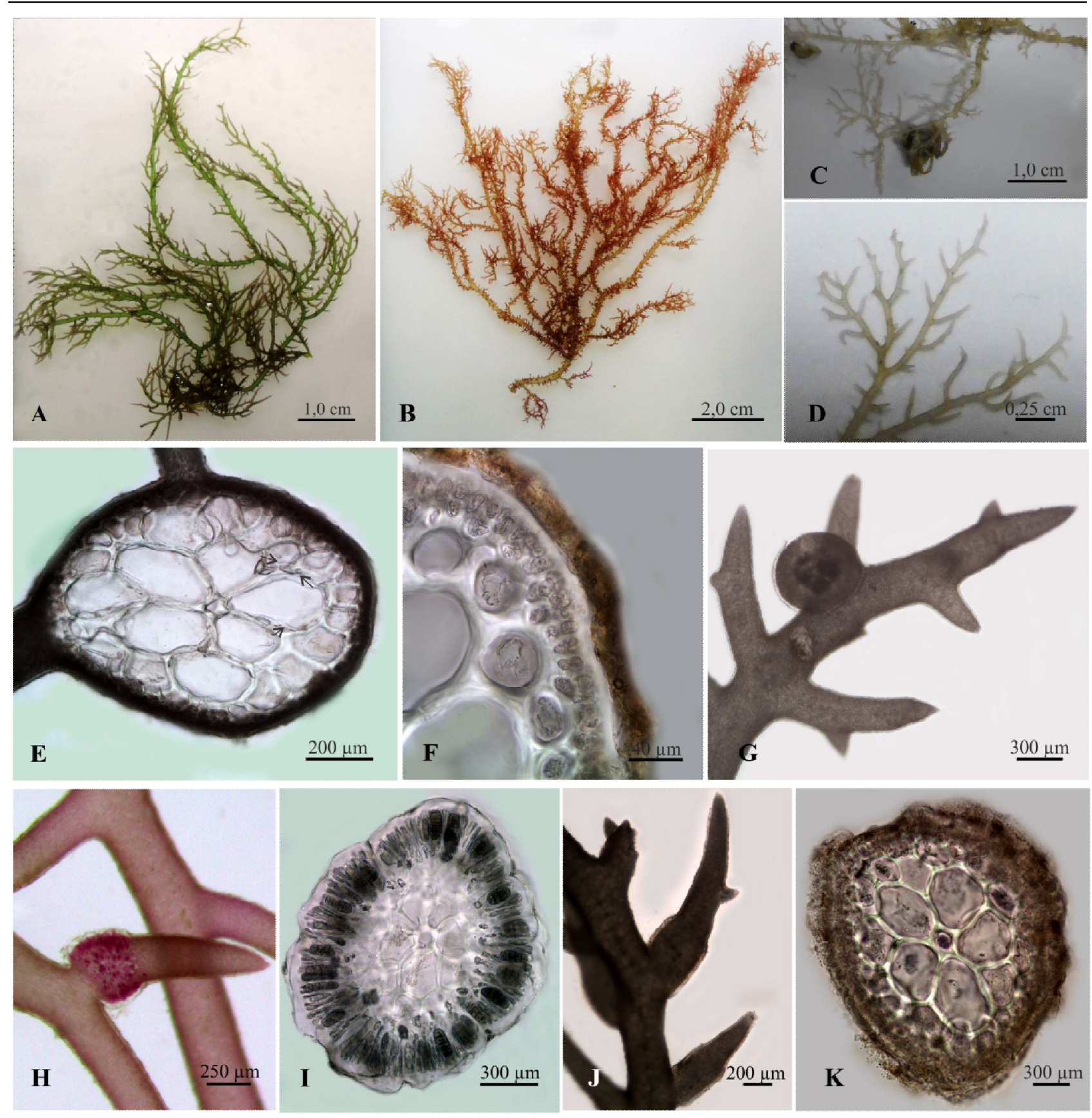

Figura 3. Hypnea cervicornis (ALCB 100217, 100218, 100200-100224): A- hábito de um exemplar estéril; B- hábito de um exemplar tetrasporofítico; C- detalhe da região basal de uma planta; D- região apical mostrando a ramificação alterna com tendência à dística; E- corte transversal do eixo principal, notar espessamentos lenticulares nas células periaxiais (setas); F- células corticais em corte transversal; Gramo portando cistocarpo; H- râmulo fértil com a região basal alargada pelo desenvolvimento dos tetrasporângios; I- corte transversal de um râmulo fértil mostrando os tetrasporângios zonados dispostos na região cortical; J- râmulos férteis com a região basal alargada pelo desenvolvimento dos espermatângios; K- corte transversal de um râmulo fértil mostrando a disposição dos espermatângios na região cortical.

A coespecificidade sugerida por Haroun \& Prud'Home van Reine (1993) foi seguida por Chiang (1997), Yamagishi \& Masuda (1997) e Wynne (1998, 2005). Entretanto, Bangmei \& Yongqiang (1997) e Abbott (1999) foram alguns dos autores que desconsideraram os comentários sobre a possível coespecificidade e continuaram a reconhecer Hypnea cervicornis. Abbott (1999) disse que manter $H$. cervicornis como entidade a parte é uma medida conservadora quando não se é capaz de examinar o material estudado por Haroun \& Prud'homme van Reine.
Wynne (2011) passou a considerar Hypnea cervicornis como uma espécie independente de H. spinella baseado nas diferenças morfológicas apontadas por Guimarães (2006) para distingui-las na flora brasileira: H. cervicornis apresentando talo laxo, formando aglomerados emaranhados com eixos livres, e H. spinella, formando densas almofadas, com eixos interligados uns aos outros por anastomoses. Neste estudo, estes dois táxons são tratados como espécies distintas. 


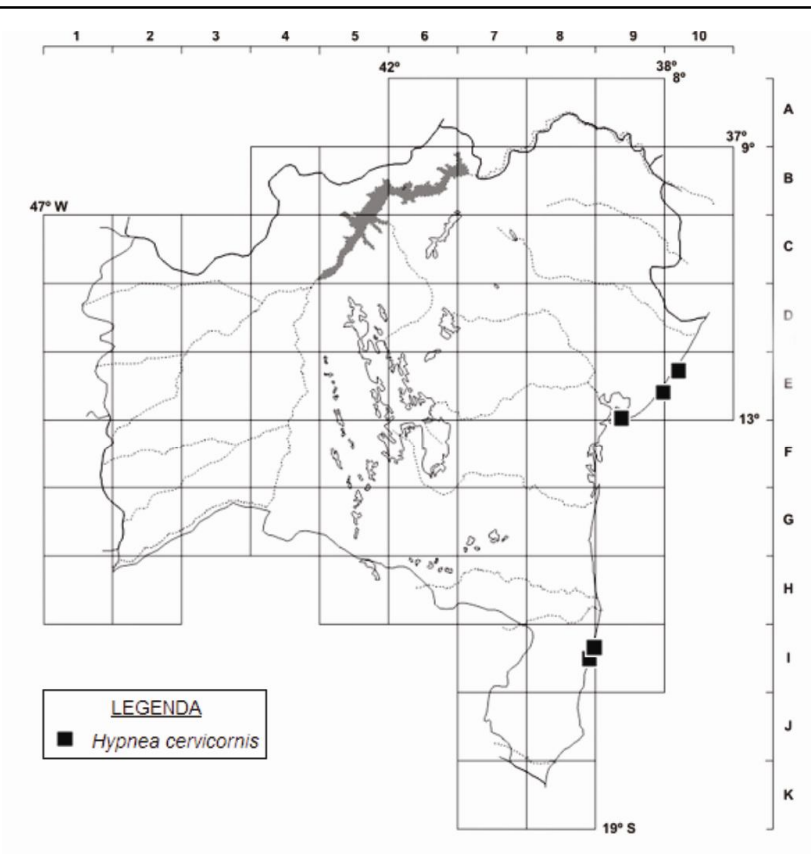

Figura 4. Mapa de distribuição de Hypnea cervicornis no litoral do estado da Bahia.

3. Hypnea cornuta (Kützing) J.Agardh, Sp. Alg. 2(2): 449. 1852. Chondroclonium cornutum Kützing, Sp. Alg.: 741.1849.

Figuras 5 e 6.

Talo ereto, textura cartilaginosa, coloração amarela amarronzada, até $15 \mathrm{~cm}$ alt. Fixo ao substrato através de ramos rizoidais, $0,5-1,5 \mathrm{~cm}$ compr., pouco ou não ramificados, apresentando discos de fixação. Eixo principal cilíndrico e evidente, $937-1350 \mu \mathrm{m}$ diâm. Ramos laterais livres, 3-6,5 cm compr., inseridos de maneira alterna a irregular em vários planos, ramificação em ângulos abertos. Anastomoses ausentes. Ápice ereto e agudo, 371-435 $\mu \mathrm{m}$ diâm. Râmulos dispostos de maneira alterna com tendência dística. Processos estrelados peltados com 3-6 pontas e tonalidade mais escura, 712-2156 $\mu \mathrm{m}$ compr., frequentes na porção superior dos ramos e râmulos. Célula axial 29-81 $\mu \mathrm{m}$ diâm., muito menor que as periaxiais, as quais são arredondadas a ovais, em número de 5 ou $6,98-229 \mu \mathrm{m}$ diâm.; 2 ou 3 camadas de células medulares hialinas, 32-80 $\mu \mathrm{m}$ diâm.; 1 ou 2 camadas de células corticais, $17-22 \mu \mathrm{m}$ diâm. Espessamentos lenticulares abundantes nas paredes das células periaxiais e/ou medulares, até $57 \mu \mathrm{m}$ compr. Cutícula muito espessa em volta de todo o talo, 29-57 $\mu \mathrm{m}$ de espessura em corte transversal, até 116 $\mu \mathrm{m}$ em vista superficial. Tetrasporângios 38-63 $\mu \mathrm{m}$ compr. $\times 23-47 \mu \mathrm{m}$ diâm., circundando a porção basal e mediana dos râmulos. Exemplares gametofíticos não encontrados.

Joly et al. (1968) foram os primeiros a referirem esta espécie no litoral brasileiro para o estado do Rio de Janeiro. Os demais estudos que faziam referência a este táxon no país (Yoneshigue-Valentin 1985; Schenkman 1986; Reis-Santos 1990) encontravam-se sob a forma de Teses ou Dissertações e não contavam com dados morfológicos e/ou ilustrações detalhadas. Jesus \& Nunes (2012), através de análise de exemplares coletados pela primeira vez no estado da Bahia e exame de espécimes depositados em herbários brasileiros, comprovaram ampla distribuição de Hypnea cornuta no estado do Rio de Janeiro, além de confirmarem sua ocorrência para o litoral dos estados do Maranhão, São Paulo e Paraná. I8/9: mediolitoral, em locais protegidos da arrebentação das ondas, ocorrendo solitárias ou formando densas populações, geralmente associadas a Hypnea cervicornis e epifitadas por cianofíceas.

Material selecionado - Santa Cruz Cabrália, Coroa Vermelha, 8 nov. 2010, P.B. Jesus et al. (ALCB 100215, 100216-Ø).

Material adicional examinado - BRAZIL. MARANHÃO. Recife do Timbuba, 3 nov. 1982 M.M. Ferreira-Correia (SP 187768). RIO DE JANEIRO. Búzios, Ponta do Lagoinha, 19 fev. 1981, Y. Yoneshigue-Valentin (RFA 2622, 2623); Ponta do Costa, $12 \mathrm{dez}$. 1986, R.P. Reis-Santos (RB 270155); Saco do Sorita, 12 dez. 1986, R.P. Reis-Santos (RB 270159, 270160); Paraty, Ilha Comprida, 25 nov. 1985, M.A.O. Figueiredo (RB 281965). SÃO PAULO. São Sebastião, Praia do Araçá, 29 set. 1983, R.P.F. Schenkman (SPF 26864, como H. valentiae). PARANÁ. Ilha do Mel, Saco do Limoeiro, 4 dez. 1983, E.C. Oliveira \& E. Plastino (SPF 28783, H. valentiae).

Os exemplares encontrados no litoral da Bahia foram facilmente identificados como Hypnea cornuta por apresentarem os râmulos estrelados característicos desta espécie. Estes râmulos são proeminentes e exibem coloração mais escura que o restante do talo, constituindo uma característica diagnóstica importante (Agardh 1852; Masuda et al. 1997). Cecere et al. (2004, 2011) comprovaram que esses râmulos estrelados funcionam como propágulos, sendo responsáveis pela reprodução vegetativa e rápida

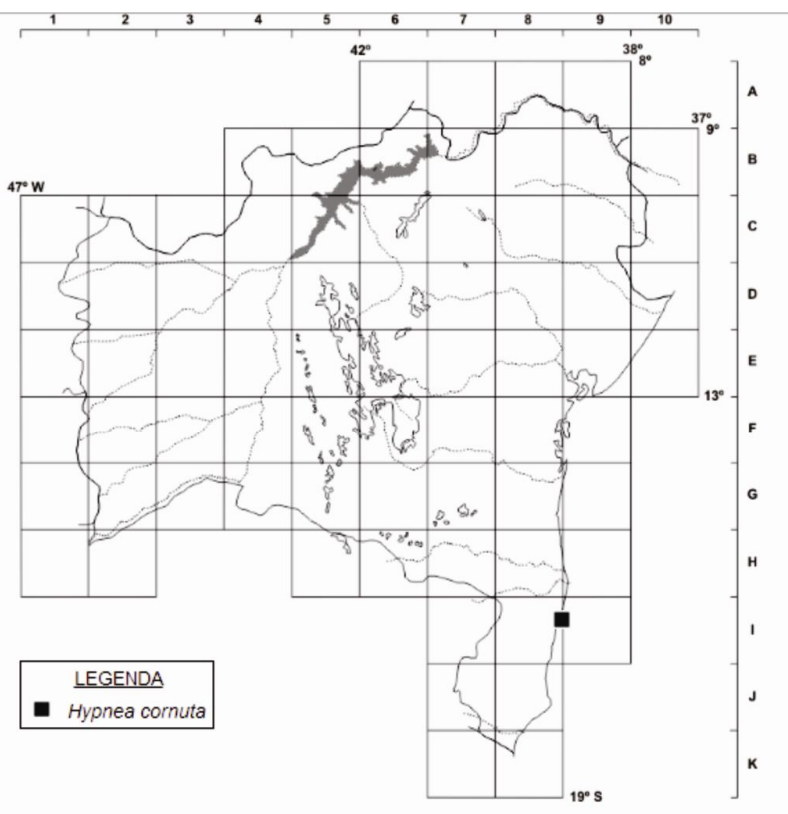

Figura 5. Mapa de distribuição de Hypnea cornuta no litoral do estado da Bahia. 


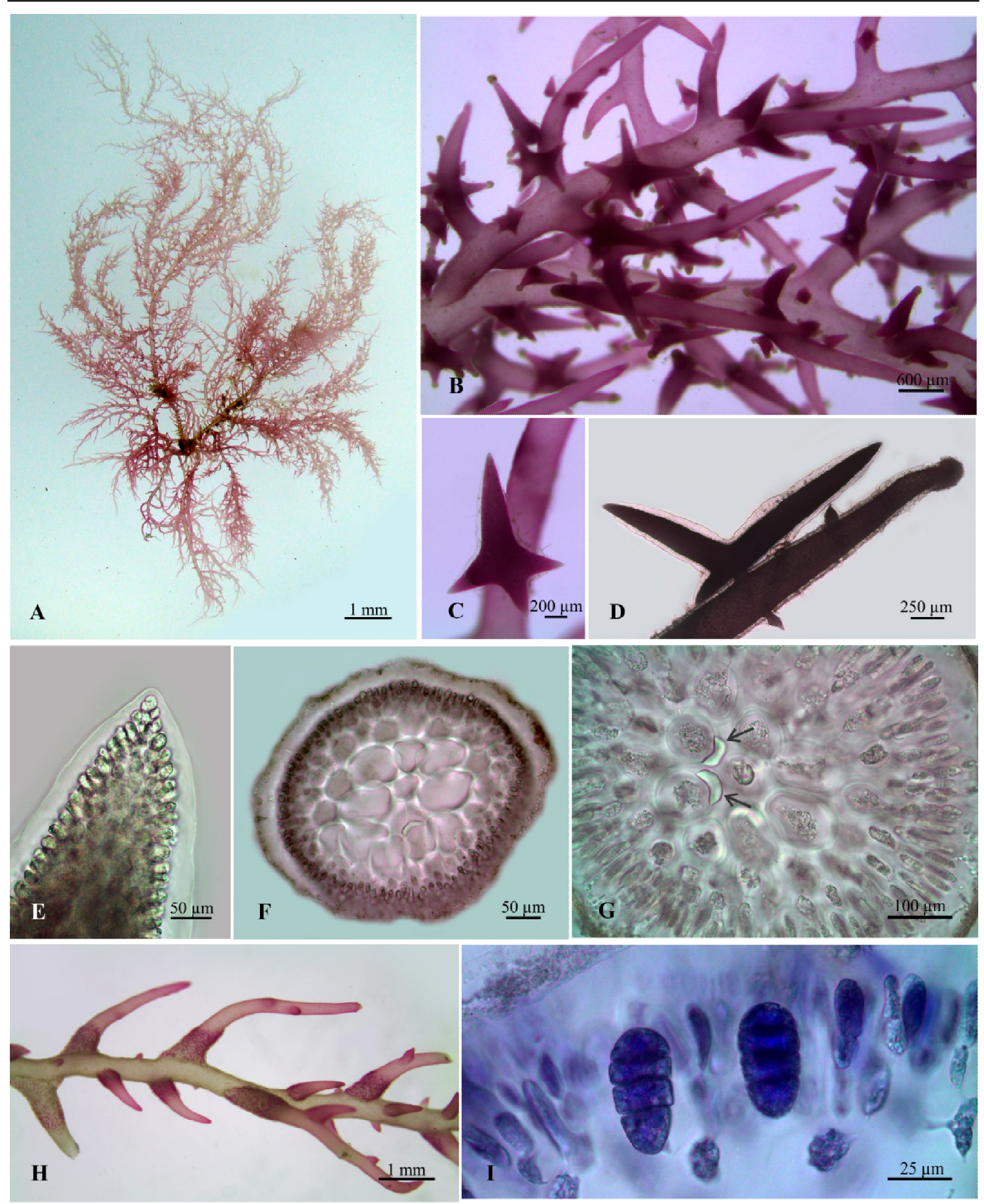

Figura 6. Hypnea cornuta (ALCB 100215, 100216): A- aspecto geral; B- ramos superiores portando râmulos estrelados; C- detalhe de um râmulo estrelado; D- vista lateral de um râmulo estrelado evidenciando a constrição basal; E- ápice de um ramo secundário, notar cutícula espessa; F- corte transversal na região apical de um ramo, notar cutícula espessa; G- corte transversal de um râmulo fértil em estágio inicial de desenvolvimento dos tetrasporângios, notar espessamento lenticular evidente nas paredes de células periaxiais (setas); H- soros tetrasporangiados desenvolvidos na região basal dos râmulos; I- região cortical de um râmulo fértil evidenciando dois tetrasporângios zonados maduros. 
disseminação da espécie. A presença de uma cutícula espessa transparente (Joly et al. 1968; Cecere et al. 2004; Jesus \& Nunes 2012), evidente tanto em vista superficial (Figura 6E), quanto em corte transversal (Figura 6F), também é uma característica bastante peculiar de $H$. cornuta, auxiliando na sua diferenciação em relação às demais espécies do gênero.

$\mathrm{O}$ material analisado concorda com as descrições e ilustrações fornecidas por Agardh (1852), Tanaka (1941), Taylor (1960), Ogawa \& Lewmanomont (1981), Mshigeni \& Chapman (1994), Wynne (1995), Chiang (1997), Masuda et al. (1997), Cecere et al. (2004), Dawes \& Mathieson (2008).

4. Hypnea musciformis (Wulfen) J.V.Lamouroux, Ann. Mus. Natl. Hist. Nat. 20: 131. 1813. Fucus musciformis Wulfen in Jacquin, Coll. Bot. Chem. Hist. Nat, Sept. 3: 154. 1789.

Figuras 7 e 8.

Talo geralmente epifítico, ereto, textura membranácea a cartilaginosa, coloração vinácea, esverdeada ou amarronzada, 4-7(-15) $\mathrm{cm}$ alt. Fixo ao substrato através de disco de fixação primário, gavinhas ou estolão de onde partem ramos eretos. Eixos cilíndricos dividindo-se várias vezes, sendo difícil reconhecer um único eixo principal, 342-690 $\mu \mathrm{m}$ diâm. Ramos (2-)4-9 cm compr., inseridos de maneira irregular em vários planos. Anastomoses ausentes. Ápices dos eixos principais e ramos primários e secundários em forma de gavinhas espessas, com râmulos na região dorsal, dispostos unilateralmente. Râmulos irregularmente dispostos por todo o talo, mas geralmente formando ângulos retos com o eixo principal nas porções basais e ângulos mais fechados em direção ao ápice. Célula axial 45-85 $\mu \mathrm{m}$ diâm., de tamanho maior ou igual às periaxiais, as quais apresentam contorno circular a irregular, em número de 6-8, medindo 20-102 $\mu \mathrm{m}$ diâm. (geralmente 3-5 maiores e 3 menores); 2 ou 3 camadas de células medulares, 37-118 $\mu \mathrm{m}$ dâm.; 1 ou 2 camadas de células corticais, 9-14 $\mu \mathrm{m}$ diâm. Espessamentos lenticulares frequentes e de formato variável nas paredes das células periaxiais e/ou medulares. Tetrasporângios 43-255 $\mu \mathrm{m}$ compr. × 43-89 $\mu \mathrm{m}$ diâm., circundando a porção basal e mediana dos râmulos. Cistocarpos globosos sem constrição na base, solitários ou em grupos de 2-4 nos ramos e râmulos laterais, 467-849 $\mu \mathrm{m}$ compr. $\times 441-815 \mu \mathrm{m}$ alt; carposporângios 18,5-27 $\mu \mathrm{m}$ diâm. Pêlos hialinos em volta de toda a superfície dos tetrasporófitos e gametófitos femininos. Gametófitos masculinos não encontrados.

Amplamente distribuída em toda a extensão do litoral brasileiro (Nunes et al. 2013). D10, E9/10, E/F9, G8/9, G/H8/9, I9/10, I10: mediolitoral, formando populações densas, epífita na região frontal e protegida do recife, na laguna recifal e em poças. Encontrada em substrato arenoso, geralmente formando um estolão, crescendo sobre Amansia multifida J.V.Lamouroux, Botryocladia occidentalis (Børgesen) Kylin, Bryothamnion seaforthii (Turner) Kützing, Cryptonemia seminervis, Digenea simplex, Gelidiella acerosa, Gelidiopsis variabilis e Gracilaria sp. Associada a Caulerpa racemosa (Forsskål) J.Agardh var. macrophysa (Sonder ex Kützing) W.R.Taylor, Chondracanthus acicularis, Enantiocladia duperreyi (C.Agardh) Falkenberg, Gelidiella acerosa, Hypnea valentiae, Palisada perforata e Ulva lactuca Linnaeus. Epifitada por Acrochaetium sp., Rhodothamniella codicola (Børgesen) C.Bidoux \& F.Magne e diatomáceas.

Material selecionado - Conde, Sítio do Conde, 24 out. 2010, P.B. Jesus et al. (ALCB 10266-Ø); Mata de São João, Praia do Forte, 25 set. 2010, P.B. Jesus et al. (ALCB 100264-Ø, 100265-Ø, 100266-Ø), Imbassaí, P.B. Jesus et al. (ALCB 100192-Ø, 100263†); Camaçari, Praia do Emissário, 23 set. 2010, P.B. Jesus et al. (ALCB 100267); Lauro de Freitas, Villas do Atlântico, 12 ago. 2010, P.B. Jesus et al. (ALCB 100195-Ø); Salvador, Stella Maris, 24 set. 2010, P.B. Jesus et al. (ALCB 100193-Ø), 19 fev. 2011, P.B. Jesus et al. (ALCB 100270-Ø), 27 dez. 2011, P.B. Jesus et al. (ALCB 100272-Ø); Ilha de Itaparica, Vera Cruz, Mar Grande, 4 dez. 2010, P.B. Jesus et al. (ALCB 100274-Ø, 100275), Penha, 5 dez. 2010, P.B. Jesus et al. (ALCB 10277-Ø); Itacaré, Havaízinho, 19 abr. 2011, P.B. Jesus et al. (ALCB 100282-9); Uruçuca, Serra Grande, 18 abr. 2011, P.B. Jesus et al. (ALCB 100278, 100279-Ø, 100280-甲); Ilhéus, Gravatá, 17 abr. 2011, P.B. Jesus et al. (ALCB 100281-Ø); Santa Cruz Cabrália, Apuã, 5 nov. 2010, P.B. Jesus et al. (ALCB 100283-Ø), Coroa Vermelha, 7 nov. 2010, P.B. Jesus et al. (ALCB 100199, 100284-Ø, 100285†); Porto Seguro, Arraial D'Ajuda, Mucugê, 6 nov. 2010, P.B. Jesus et al. (ALCB 100286, 100287-Ø).

Hypnea musciformis é a espécie-tipo e a mais estudada do gênero. A presença de ápices em forma de gavinhas dilatadas é a característica diagnóstica da espécie, que possui ampla variação morfológica. Espécimes de locais calmos são mais delicados (Figura 7A), menos ramificados, podendo desenvolver estolões para fixação ao substrato; enquanto os de locais expostos são geralmente mais robustos, intensamente ramificados e emaranhados (Figura 7B). A coloração do talo é outra característica que apresenta ampla variação.

Schneider \& Searles (1991) ressaltaram que esta espécie exibe grande plasticidade morfológica não só entre as populações, mas também dentro delas. Os autores afirmaram que alguns exemplares podem ser primariamente confundidos com Hypnea valentiae quando não apresentam os ápices em forma de gavinha. A disposição dos râmulos em ângulos retos nas porções basais do talo, a baixa densidade de râmulos no ápice e o padrão anatômico visto em corte transversal (Tabela 1) auxiliam no reconhecimento desta espécie. 

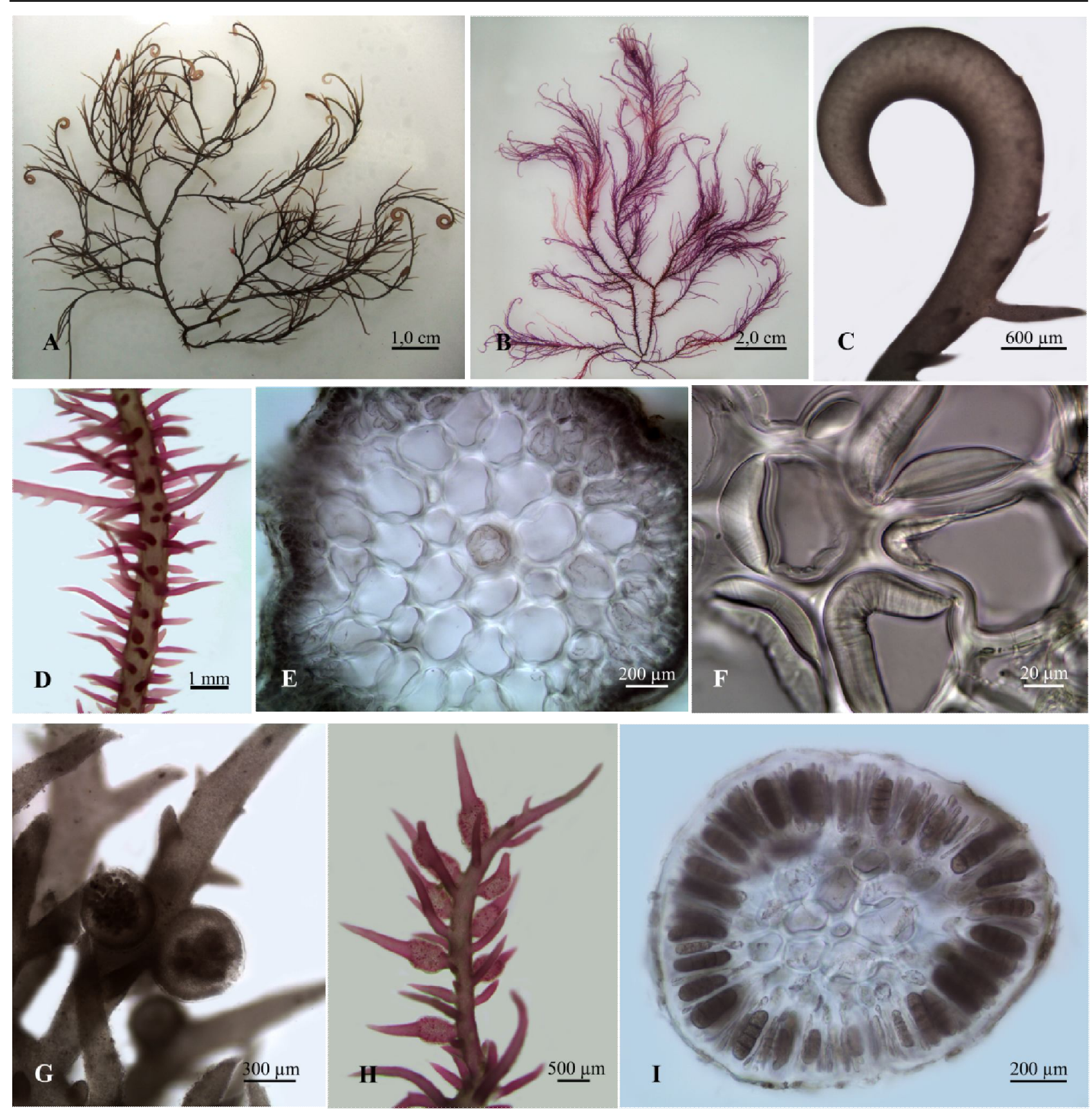

Figura 7. Hypnea musciformis (ALCB 100264, 100267, 100270, 100278, 100279, 100282, 100285): A- aspecto geral de um exemplar típico de regiões com baixo hidrodinamismo; B- aspecto geral de um exemplar típico de regiões com alto hidrodinamismo; C- detalhe do ápice de um ramo em forma de gavinha; D- râmulos inseridos em ângulos retos na porção basal do talo; E- corte transversal na região basal de um ramo; F- espessamentos lenticulares nas células medulares; G- cistocarpo nos râmulos; H- soros tetrasporangiados; I- corte transversal de um râmulo fértil mostrando a disposição dos tetrasporângios na região cortical.

Embora Hypnea musciformis esteja incluída em praticamente todas as floras regionais do litoral brasileiro, faltam estudos taxonômicos detalhados que forneçam caracteres morfológicos e anatômicos para a correta delimitação da espécie. A ausência das gavinhas pode resultar em identificações errôneas. Além de $H$. musciformis, $H$. nigrescens e $H$. valentiae também podem apresentar ápices recurvados, eventualmente formando ganchos. Contudo, as gavinhas de $H$. musciformis são sempre numerosas e bem mais dilatadas (Figura 7C), estando presentes quase sempre tanto nos eixos principais quanto nos ramos laterais. Schenkman (1980) verificou que as gavinhas de $H$. musciformis se prendiam tão fortemente à planta epifitada que, quando a planta era arrancada, suas gavinhas permaneciam aderidas à planta hospedeira e voltavam a brotar, originando novas plantas. 


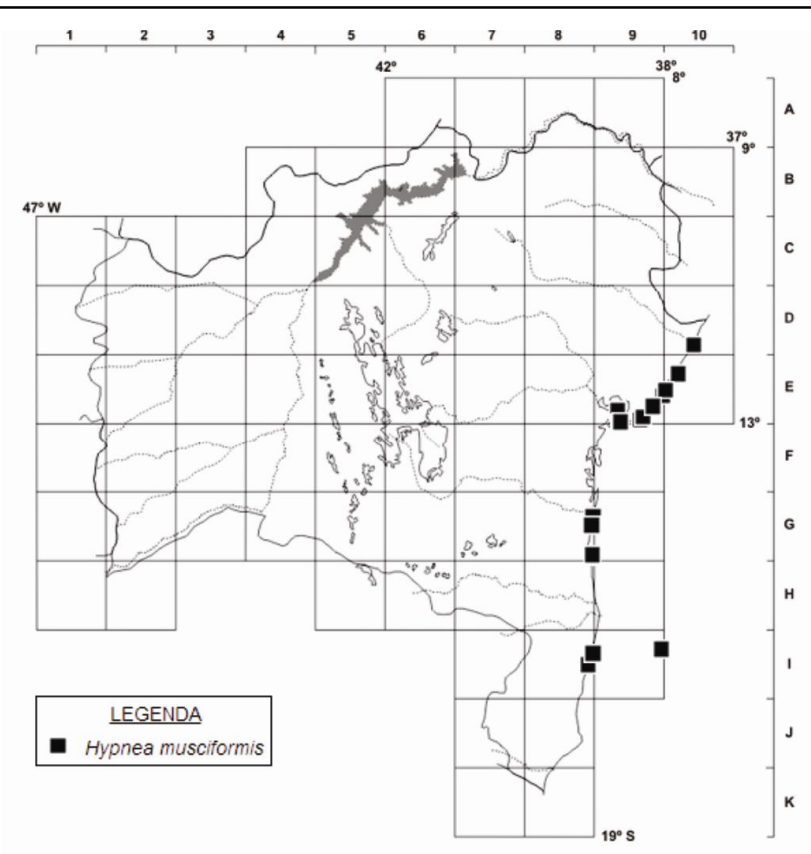

Figura 8. Mapa de distribuição de Hypnea musciformis no litoral do estado da Bahia.

5. Hypnea nigrescens Greville ex J.Agardh, Sp. Alg. 2 (2): 443.1852.

Figuras 9 e 10.

Talo formando tufos com uma porção prostrada de onde partem ramos eretos, textura cartilaginosa, coloração verde, negro-esverdeada ou vinácea, $2,5-8 \mathrm{~cm}$ alt. Fixo ao substrato por ramos rizoidais emaranhados. Eixos principais cilíndricos e evidentes, com diâmetro maior na região mediana $(578-1.976 \mu \mathrm{m})$ que na base (447-650 $\mu \mathrm{m})$. Ramos eretos variando entre $2-7,3 \mathrm{~cm}$ alt., ramos maiores irregularmente inseridos no centro do tufo. Anastomoses ausentes. Râmulos subulados, dispostos irregularmente $0,5-1 \mathrm{~cm}$ acima da base do talo que geralmente apresenta-se lisa. Porção mediana e apical do talo intensamente ramificada de maneira irregular com tendência a espiralada, em ângulos fechados sempre direcionados para cima. Ápice geralmente reto e agudo, podendo apresentar-se recurvado ou em forma de gancho não dilatado. Célula axial 64-260 $\mu \mathrm{m}$ diâm., de tamanho similar ou maior que as periaxiais (34-215 $\mu \mathrm{m}$ diâm.), as quais apresentam contorno arredondado a irregular, em número de 6 ou 7; 2 ou 3 camadas de células medulares de formato oval-triangular a quadrático, inicialmente maiores (144-326 $\mu \mathrm{m}$ diâm.) que as periaxiais, reduzindo-se em direção à periferia; 1 ou 2 camadas de células corticais, 8,2-15 $\mu \mathrm{m}$ diâm. Espessamentos lenticulares raros. Tetrasporângios 36-167 $\mu \mathrm{m}$ compr. × 15-74 $\mu \mathrm{m}$ diâm., geralmente circundando a porção basal e mediana dos râmulos incompletamente, produzindo acentuado encurvamento destes. Cistocarpos solitários ou em grupos de 2 a 4, 357-599 $\mu \mathrm{m}$ compr. $\times$ 393-601 $\mu \mathrm{m}$ alt., sem constrição na base, 1 ou 2 camadas de células

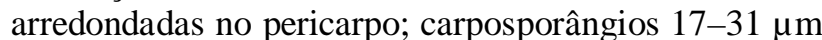
diâm. Espermatângios 4,1-6,3 $\mu \mathrm{m}$ diâm., circundando incompletamente a porção basal e mediana dos râmulos, produzindo um suave encurvamento destes.

Apesar de pouco citada em levantamentos regionais, Hypnea nigrescens aparenta ser bem distribuída ao longo da costa brasileira (Schenkman 1986; Nunes 2005; Nunes et al. 2013). D10, E9/10, E/F9, G8/9, I8/9: mediolitoral, formando extensas populações, epilítica e epífita na região frontal e protegida do recife e em poças. Crescendo sobre Jania cubensis Montagne ex Kützing, J. subulata (Ellis \& Solander) Sonder e J. adhaerens J.V.Lamouroux. Associada à Palisada perforata e Anadyomene stellata (Wulfen) C.Agardh. Epifitada por cianofíceas e diatomáceas da ordem Centrales.

Material selecionado - Conde, Sítio do Conde, 4 out. 2010, P.B. Jesus et al. (ALCB 100202-Ø, 100203-9); Entre Rios, Subaúma 25 out. 2010, P.B. Jesus et al. (ALCB 100208-Ø, 100209+, 100214-ð); Camaçari, Praia do Emissário, 23 set. 2010, P.B. Jesus et al. (ALCB 100196, 100211, 100212-Ø, 100197, 100210, 100213-甲); Itacaré, Havaízinho, 19 abr. 2011, P.B. Jesus et al. (ALCB 100220); Uruçuca, Serra Grande, 18 abr. 2011, P.B. Jesus et al. (ALCB 100204-Ø, 100205-9); Ilhéus, Gravatá, 17 abr. 2011, P.B. Jesus et al. (ALCB 100206-Ø, 100207-昂); Santa Cruz Cabrália, Praia de Apuã, 5 nov. 2010, P.B. Jesus et al. (ALCB 100201, 100242-9).

Os exemplares de Hypnea nigrescens podem ser facilmente reconhecidos em campo pelo hábito, coloração esverdeada ou enegrecida e, como assinalado por Schenkman (1986), pelos ramos semelhantes a cerdas de um pincel. Além destas características, a presença de ramos maiores inseridos no centro do tufo (Figura 10A), a ausência de ramificação na região basal dos eixos (Figura 10B), e a disposição dos tetrasporângios nos râmulos (Figura 10G) foram essenciais para a identificação dos exemplares. Estas características concordam com as apontadas por Agardh (1852), Schenkman (1986) e Nunes (2005).

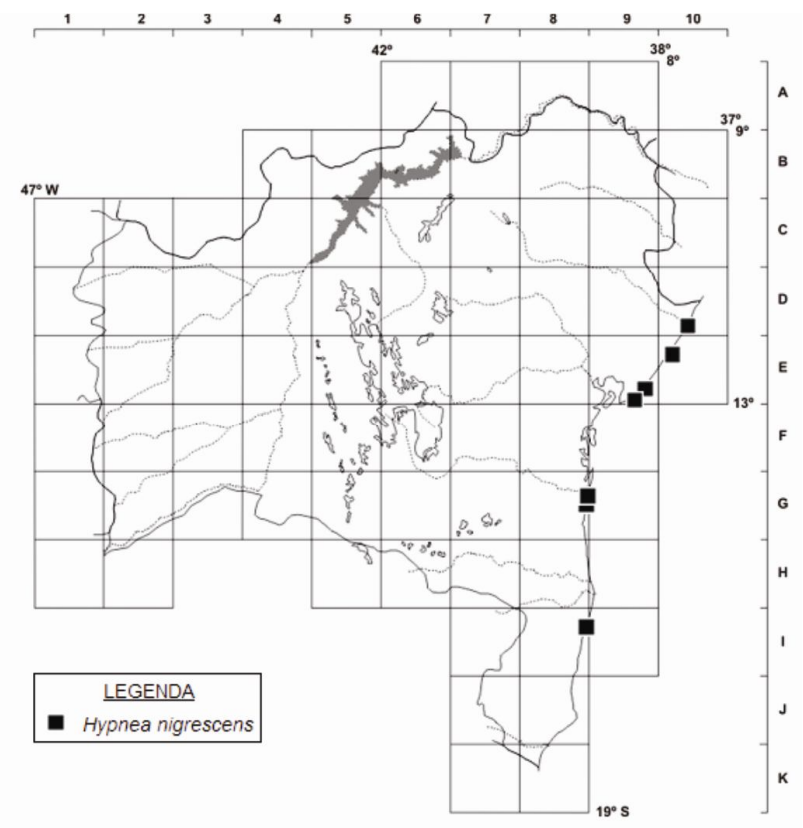

Figura 9. Mapa de distribuição de Hypnea nigrescens no litoral do estado da Bahia. 

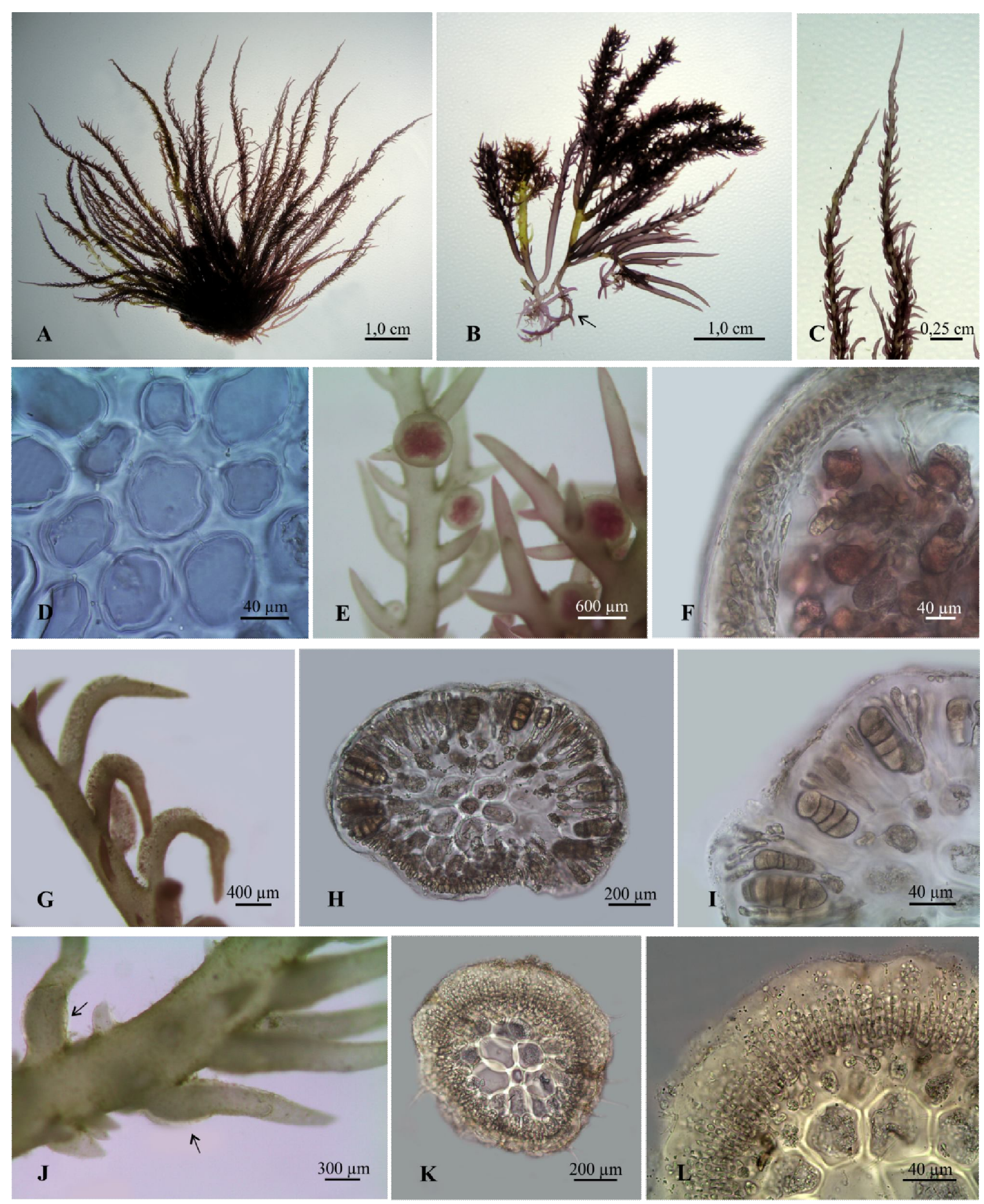

Figura 10. Hypnea nigrescens (ALCB 100196, 100202, 100203, 100214, 100242): A- hábito de um exemplar tetrasporofítico; B- exemplar cistocárpico com a região basal desnuda, após remoção de algas associadas, evidenciando a porção rizoidal (seta) e a base dos ramos mais estreitas que o restante do talo; C- detalhe dos ramos eretos portando râmulos subulados; D- corte transversal na base do talo evidenciando uma grande célula axial e sete periaxiais; E- râmulos portando cistocarpos; F- corte longitudinal de um cistocarpo evidenciando o pericarpo e os carpósporos; G- râmulos curvados pelo desenvolvimento de tetrasporângios circundando-os incompletamente; H- corte transversal de um râmulo fértil mostrando os tetrasporângios; I- detalhe dos tetrasporângios zonados; J- râmulos portando espermatângios; K- corte transversal de um râmulo fértil mostrando a disposição dos espermatângios; L- detalhe dos espermatângios produzidos em cadeia na região cortical dos râmulos. 
A presença de râmulos recurvados e eixos principais terminados em gavinhas em espécimes de Hypnea nigrescens podem confudi-la com H. musciformis. Entretanto, mesmo as gavinhas estando presentes, elas podem ser facilmente diferenciadas daquelas encontradas em $\mathrm{H}$. musciformis, pois são esparsas e geralmente apresentam diâmetro similar ao restante do talo. Apesar das duas espécies apresentarem a célula axial de tamanho maior ou igual às periaxiais, $H$. nigrescens exibe uma célula axial de tamanho geralmente maior (64-260 $\mu \mathrm{m}$ diâm.) que a de $H$. musciformis (45-85 $\mu \mathrm{m}$ diâm.). Além disso, características como hábito, padrão de ramificação, forma dos râmulos e disposição dos tetrasporângios podem auxiliar na distinção entre essas espécies (Tabela 1).

Apesar da escassez de bibliografia sobre Hypnea nigrescens, a identificação desta espécie foi possível graças à análise de sua descrição original (Agardh 1852) e as descrições e ilustrações fornecidas por Schenkman (1986) e Nunes (2005) para exemplares do litoral brasileiro. A análise do holótipo de $H$. nigrescens (E 429124) e de amostras coletadas no estado de São Paulo (E 425856; Schenkman 1986) confirmaram a identificação dos espécimes da Bahia.

6. Hypnea platyclada Jesus \& Nunes, Phytotaxa 85(1): 26-34. 2013.

Figuras 11 e 12 .

Talo prostrado, textura firme, coloração rósea, $1-3 \mathrm{~cm}$ alt. Fixo ao substrato através de uma porção estolonífera cilíndrica e vários discos de fixação, aderindo-se quase completamente à planta hospedeira. Ramos inseridos irregularmente, formados por um pedúnculo cilíndrico (667-911 $\mu \mathrm{m}$ diâm.) e porções superiores fusiformes achatadas, 108-2.046 $\mu \mathrm{m}$ larg. $\times$ 99-644 $\mu \mathrm{m}$ de espessura. Anastomoses frequentes. Râmulos 0,5-3,5 mm compr., produzidos na margem dos eixos. Células do filamento central pigmentadas, fornecendo um aspecto de nervura às porções achatadas do talo. Ápice agudo com pêlos unicelulares em volta. Célula axial oval, 54-212 $\mu \mathrm{m}$ compr. $\times$ 19-76 $\mu$ m diâm., 5 ou 6 periaxiais ovais, 244-276 $\mu$ m compr. $\times$ 88-144 $\mu \mathrm{m}$ diâm.; 2 camadas de células medulares de formato variável, oval a circular, 73-113 $\mu \mathrm{m}$ compr. $\times$ 90-174 $\mu \mathrm{m}$ diâm.; uma camada de células corticais que, em vista superficial, apresentam tamanho variável entre 8-65 $\mu \mathrm{m}$ diâm. Espessamentos lenticulares restritos às extremidades das células do filamento central. Tetrasporângios $73-99 \mu \mathrm{m}$ compr. $\times$ 41-47 $\mu \mathrm{m}$ diâm., dispostos apenas de um lado dos râmulos. Cistocarpos de base levemente constricta, 833-934 $\mu \mathrm{m}$ compr. $\times$ 714-826 $\mu \mathrm{m}$ diâm.; carposporângios 25-43 $\mu \mathrm{m}$ diâm. Espermatângios 1,4-3,7 $\mu \mathrm{m}$ diâm., dipostos apenas de um lado dos râmulos.

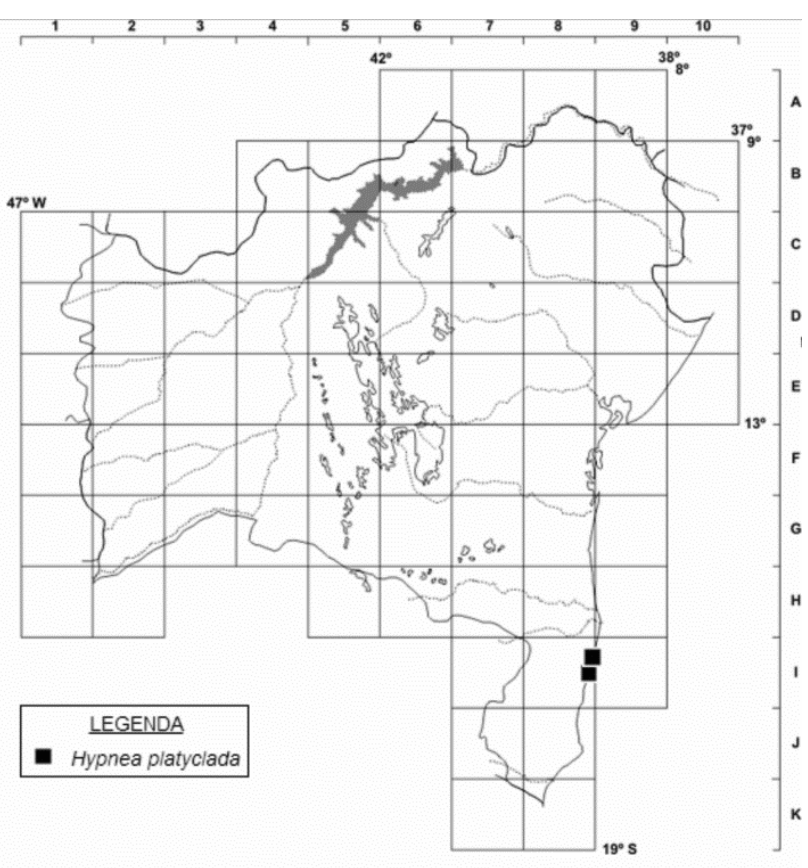

Figura 11. Mapa de distribuição de Hypnea platyclada no litoral do estado da Bahia.

Conhecida apenas para o estado da Bahia. I8/9: mediolitoral, região frontal do recife e em poças. Crescendo sobre Corynomorpha clavata (Harvey) J.Agardh, Cryptonemia seminervis (C.Agardh) J.Agardh, Gelidiopsis variabilis (Greville ex J.Agardh) F.Schmitz, Jania sp., Laurencia arbuscula Sonder e Thuretia bornetii Vickers. Associada a Amphiroa fragilíssima (Linnaeus) J.V.Lamouroux. Epifitada por Ceramium sp. e Griffithsia globulifera Harvey ex Kützing.

Material selecionado - Santa Cruz Cabrália, Apuã, 9 mar. 2001, J.M.C. Nunes \& G.M. Lyra (ALCB 53324-, 53325-Ø - Holótipo!, 100189-Ø, 100190- + , 100191-Ø); Porto Seguro, Arraial D'Ajuda, Mucugê, 12 mar. 2001, J.M. C. Nunes et al. (ALCB 53323-ô, 53326).

Material adicional examinado: Hypnea volubilis Searles ESTADOS UNIDOS DA AMÉRICA. CAROLINA DO NORTE. Onslow Bay, 4 mar. 1971, R.B. Searles (DUKE 14135 - Holótipo!, 14134-Ø-Isótipo!).

Hypnea platyclada possui uma combinação de características morfológicas que a distingue das demais espécies estudadas: pedúnculo cilíndrico e porções superiores achatadas; filamento central evidente fornecendo aspecto de nervura aos ramos; tetrasporângios e espermatângios dispostos unilateralmente na região cortical dos râmulos; células corticais de tamanho desigual e espessamentos lenticulares restritos às extremidades das células do filamento central.

7. Hypnea spinella (C.Agardh) Kützing, Bot. Zeit. 5: 23. 1847. Sphaerococcus spinellus C.Agardh, Sp. Alg. 1(2): 323. 1822.

Figuras 13 e 14. 

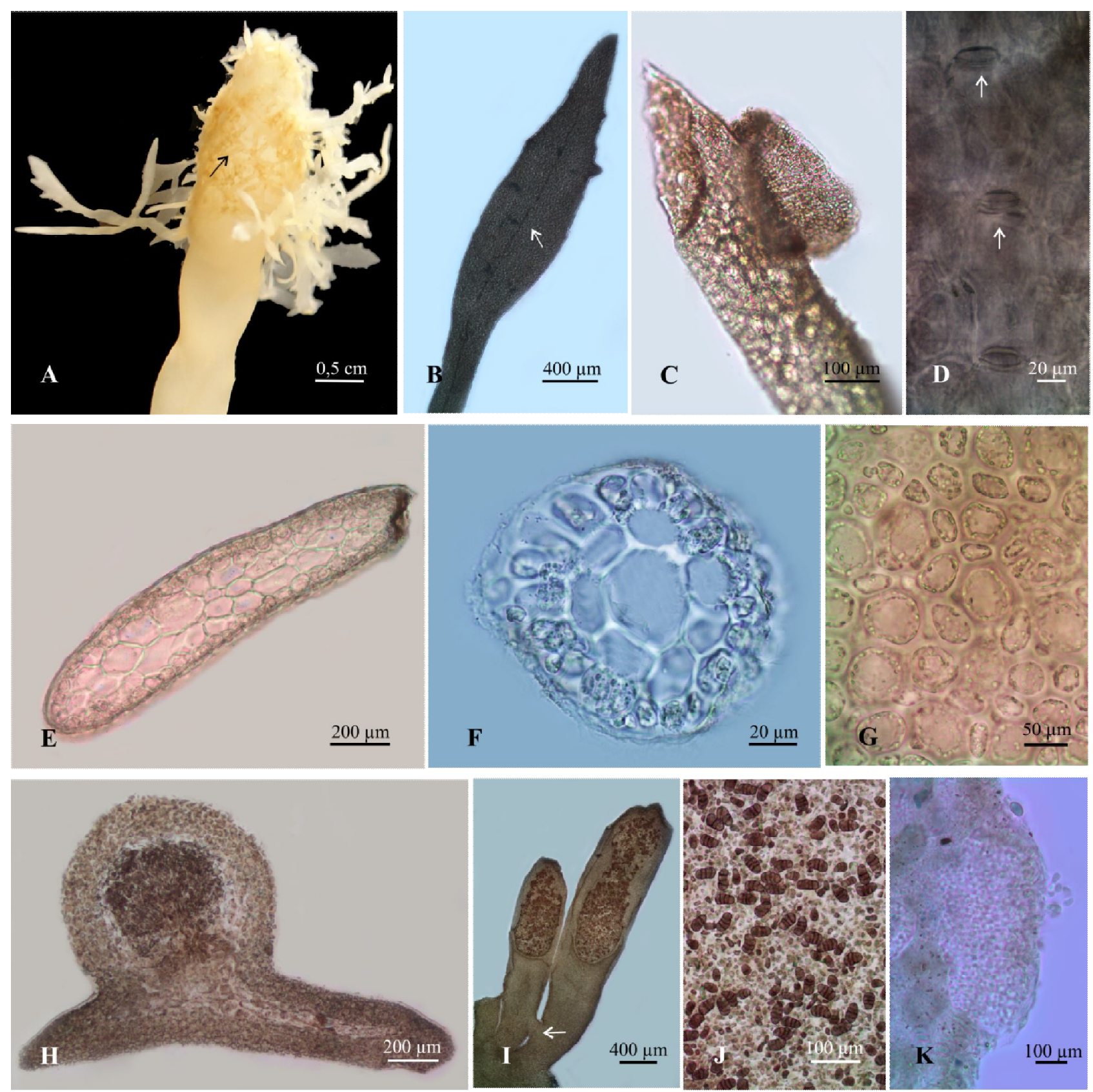

Figura 12. Hypnea platyclada (ALCB 53323-53326, 100189-100191): A- exemplar crescendo sobre Corynomorpha clavata, notar porções cilíndricas completamente aderidas à alga hospedeira (seta); B- detalhe de um ramo com nervura central evidente (seta); C- disco de fixação na porção cilíndrica do talo; D- espessamentos lenticulares (setas) nas extremidades das células do filamento central; E- corte transversal na região mediana de um ramo; F- corte transversal na porção basal cilíndrica de um ramo; G- células corticais de tamanho desigual em vista superficial; H- corte longitudinal de um cistocarpo; I- corte longitudinal de soros de tetrasporângios formados no ápice dos ramos, notar anastomose (seta) entre os ramos; J- detalhe dos tetrasporângios zonados; K- detalhe do corte transversal de um ramo portando espermatângios.

Talo prostrado, formando tufos emaranhados, $1,5-5,5(-12) \mathrm{cm}$ compr. $\times 0,5-3 \mathrm{~cm}$ alt., textura membranácea a cartilaginosa, coloração de róseoesverdeada a róseo-vinácea. Fixo ao substrato através de inúmeros discos de fixação. Eixo principal evidente ou não; quando distinto, o eixo principal geralmente apresenta coloração mais clara que os ramos e râmulos. Ramos $1-4,5 \mathrm{~cm}$ compr. $\times$ 393-1.484 $\mu \mathrm{m}$ diâm., frouxamente entrelaçados, recurvando-se para todos os lados e para o substrato; ramificação irregular em vários planos, formando ângulos retos na porção basal e agudos próximo ao ápice. Anastomoses muito frequentes. Râmulos dispostos de maneira irregular a alterna. Ápice 200-278 um diâm., agudo, reto, recurvado, e por vezes, bifurcado. Célula axial 36-45 $\mu \mathrm{m}$ diâm., muito menor que as periaxiais, as quais são em número de 5 ou 6, de formato oval-triangular medindo 74-236 $\mu$ m diâm.; 1 ou 2 camadas de células medulares de formato circular, menores que as periaxiais (37-114 $\mu \mathrm{m}$ diâm.); 


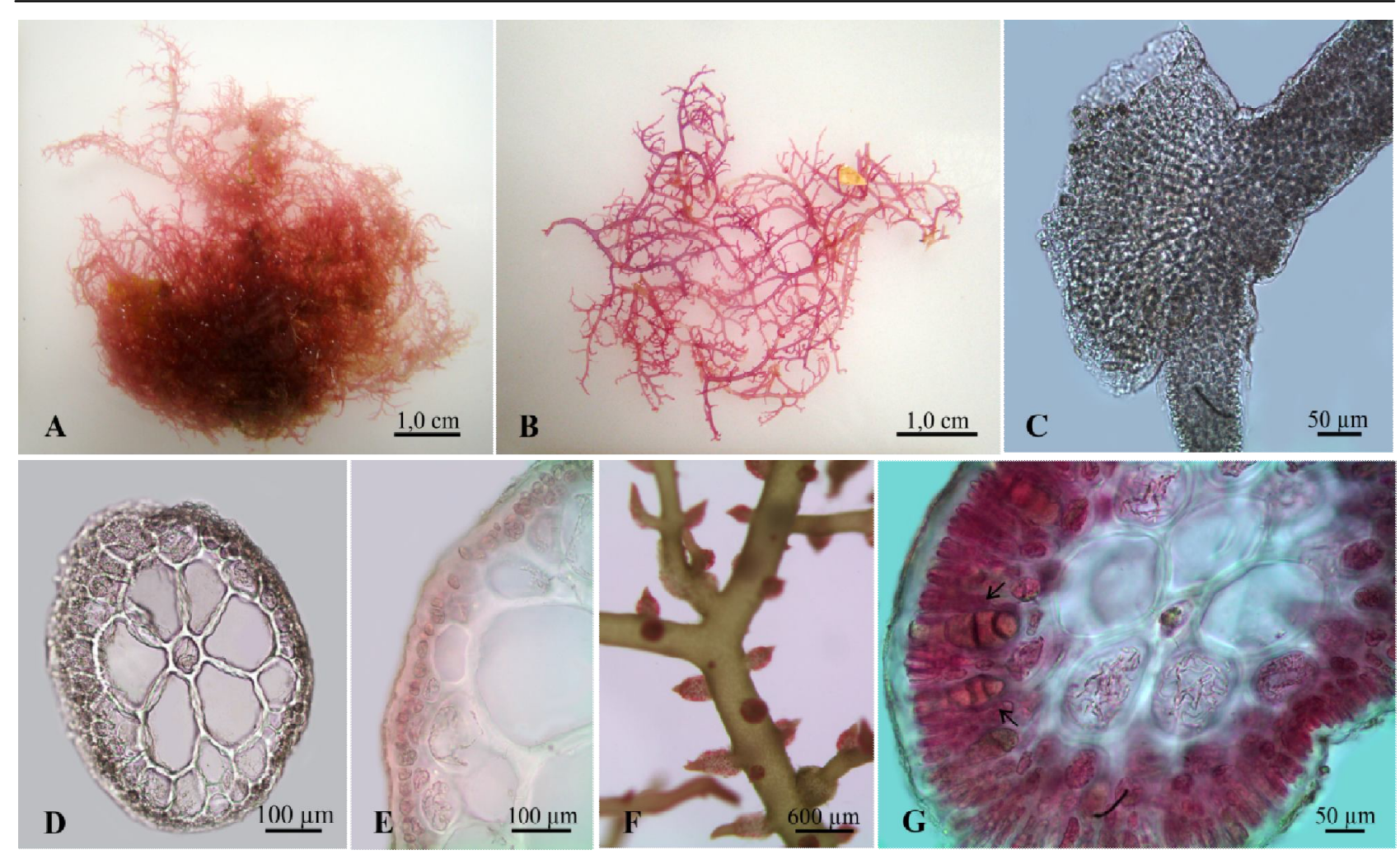

Figura 13. Hypnea spinella (ALCB 100228, 100231, 100233, 100240): A- hábito; B- detalhe dos ramos; C- disco de fixação no ápice de um ramo; D- corte transversal na base do talo evidenciando uma célula axial e seis periaxiais; E- células corticais em corte transversal; $\mathbf{F}$ - soros tetrasporangiados nos râmulos; G- corte transversal de um râmulo fértil evidenciando os tetrasporângios zonados em várias etapas do desenvolvimento na região cortical (setas).

1 ou 2 camadas de células corticais, 5-16 $\mu$ m diâm. Espessamentos lenticulares nas células periaxiais e medulares presentes na região basal e mediana do talo. Tetrasporângios 69-114 $\mu \mathrm{m}$ compr. $\times$ 41-64 $\mu \mathrm{m}$ diâm., geralmente circundando a porção apical dos râmulos ou a porção mediana ou basal; râmulos férteis podem apresentar os ápices bifurcados ou ramificados. Exemplares gametofíticos não encontrados.

Amplamente distribuída no litoral brasileiro (Nunes et al. 2013). E9/10, E/F9, G8/9, G/H8/9, I8/9: mediolitoral, epilítica na região frontal e protegida do recife e em poças. Geralmente encontradas em fendas no recife, em locais sujeitos à forte arrebentação das ondas. Crescendo sobre Amphiroa fragilissima, Chondracanthus acicularis e Laurencia sp. Associada a Jania adhaerens, Griffithsia schousboei Montagne e Ulva rigida C.Agardh. Epifitada por Centroceras clavulatum, Ceramium brevizonatum H.E.Petersen var. caraibicum H.E.Petersen \& Børgesen, Lyngbia sp., Polysiphonia sp. e briozoários.

Material selecionado - Camaçari, Praia do Emissário, 23 set. 2010, P.B. Jesus et al. (ALCB 100228); Itha de Itaparica, Vera Cruz, Mar Grande, 4 dez. 2010, P.B. Jesus et al. (ALCB 100231-Ø, 100233), Penha, 5 dez. 2010, P.B. Jesus et al. (ALCB 100232-Ø); Uruçuca, Serra Grande, 18 abr. 2011, P.B. Jesus et al. (ALCB 100236-Ø); Santa Cruz Cabrália, Apuã, 5 nov. 2010, P.B. Jesus et al. (ALCB 100230, 100240-Ø); Porto Seguro, Arraial D’Ajuda, Mucugê, P.B. Jesus et al. (ALCB 100234).

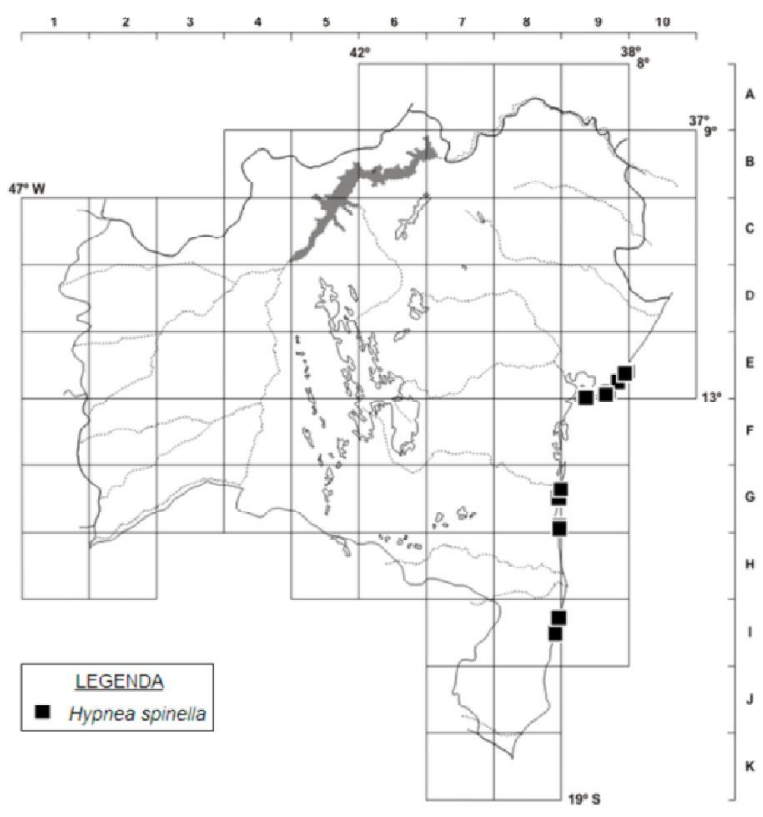

Figura 14. Mapa de distribuição de Hypnea spinella no litoral do estado da Bahia.

Conforme tratado anteriormente, há grande confusão na literatura no que diz respeito às espécies Hypnea spinella e $H$. cervicornis. Lawson \& John (1987) relataram que a confusão é tão antiga que poderia estar retratada na ilustração original de H. spinella (Kützing 1868, pl. 26, figs d-f). Como são 
ilustrados o padrão de ramificação, a forma dos ápices e a disposição de soros tetrasporangiados característicos de $H$. cervicornis, Lawson \& John (1987) ressaltaram que essa ilustração deveria ser corretamente atribuída à última espécie.

Haroun \& Prud'Home van Reine (1993) apontaram uma transição entre as formas reconhecidas como Hypnea cervicornis e $H$. spinella devido ao hidrodinamismo, propondo então a sinonímia destes táxons sob o nome Hypnea spinella (C.Agardh) J.Agardh. Posteriormente, Silva et al. (1996) ressaltaram a correta autoria para a espécie: $H$. spinella (C. Agardh) Kützing, devido à prioridade de publicação, uma vez que o trabalho de Kützing havia sido publicado em 8 de janeiro de 1847 e o de J. Agardh apenas em 13 de janeiro do mesmo ano.

No litoral baiano, os exemplares de Hypnea spinella são encontrados tanto em locais expostos, sujeitos à intensa ação de ondas quanto em locais calmos e protegidos. Este fato foi observado por Guimarães (2006) no estado do Espírito Santo, onde a sinonímia proposta por Haroun \& Prud'Home van Reine (1993) não foi adotada, o que levou Wynne (2011), também, a considerar $H$. spinella como uma espécie independente de $H$. cervicornis.

Bangmei \& Yongqiang (1997) e Abbot (1999) ressaltaram outras características que suportam o posicionamento de Hypnea cervicornis e H. spinella como táxons distintos. Hypnea spinella é facilmente reconhecida em campo por formar densos tufos de coloração vinácea, com ramos recurvados e emaranhados na base (Figura 13B) e últimos râmulos curtos e espinescentes, com tantas anastomoses e discos de fixação secundários (Figura 13C) que dificilmente consegue-se individualizar um ramo sem danificá-lo.

Muitos autores ilustram e descrevem os soros tetrasporangiados de Hypnea spinella ocorrendo no ápice dos ramos (e.g., Price \& Scott 1992; Wynne 1995; Bangmei \& Yongqiang 1997) e Mshigeni (1978) utilizou esta característica para separar $H$. spinella de H. pannosa J.Agardh. Abbott (1999) observou que os soros tetrasporangiados dos espécimes do Havaí ocasionalmente ocorrem nos ápices dos râmulos, mas que soros de uma mesma planta podem também ser encontrados circundando o râmulo próximo à base; indicando assim, que o soro tetrasporangiado terminal não é um caráter diagnóstico para identificação. De fato, existe muita variação nesta característica e os espécimes da Bahia também apresentam disposição dos soros tanto na região apical quanto nas porções basal e mediana dos râmulos. Contudo, conforme dito anteriormente, é o conjunto de características que torna este táxon bem peculiar.
8. Hypnea valentiae (Turner) Montagne, Hist. Nat. Iles Canaries 3: 161. 1841. Fucus valentiae Turner, Fuci 2: 17.1809.

Figuras 15 e 16.

Talo ereto, abundantemente ramificado, textura membranácea a cartilaginosa, coloração róseo-vinácea ou amarronzada, $4,5-23 \mathrm{~cm}$ alt. Fixo ao substrato através de um disco de fixação primário ou por ramos rizoidais entrelaçados. Eixo principal cilíndrico e evidente, 628-1.756 $\mu \mathrm{m}$ diâm. Ramos superiores livres, 3-10 cm compr., inseridos de maneira irregular a alterna em vários planos, ramificação em ângulos abertos retos ou quase retos. Anastomoses ausentes. Râmulos $0,5-1,5 \mathrm{~cm}$ compr., dispostos de maneira espiralada ou radial, sempre direcionados para cima. Ápice 314-357 $\mu \mathrm{m}$ diâm., agudo ou por vezes, recurvado e em forma de gancho de mesma espessura que o restante do talo. Célula axial de contorno estrelado e parede espessa, 45-172 $\mu \mathrm{m}$ diâm., de tamanho igual ou menor que as periaxiais, 44-170(375) $\mu \mathrm{m}$ diâm., as quais podem apresentar contorno circular ou irregular, em número de $4-6 ; 2$ ou 3 camadas de células medulares, 58-292 $\mu \mathrm{m}$ diâm.; 1 camada de células corticais, 5-11 $\mu \mathrm{m}$ diâm. Espessamentos lenticulares abundantes nas paredes das células periaxiais e/ou medulares. Pêlos hialinos em volta de toda a superfície dos tetrasporófitos e gametófitos. Tetrasporângios 23-63 $\mu \mathrm{m}$ compr., geralmente circundando a porção basal e mediana dos râmulos, provocando alargamento desta região (859-1.186 $\mu \mathrm{m}$ diâm.). Cistocarpos sem pedúnculo, 545-787 $\mu \mathrm{m}$ compr. $\times$ 464-843 $\mu \mathrm{m}$ alt., carposporângios piriformes a esféricos, 18-27 $\mu \mathrm{m}$ diâm. Espermatângios esféricos, 1,9-5,9 $\mu \mathrm{m}$ diâm., geralmente circundando a porção basal dos râmulos, provocando alargamento desta região (692-1.153 $\mu \mathrm{m}$ diâm.).

D10, E9/10, E/F9, G8/9, I8: mediolitoral, epilítica e epífita na região frontal e protegida do recife e em poças. Crescendo sobre Amansia multifida, Bryothamnion triquetrum, Digenea simplex e Gracilaria birdiae Palastino \& E.C.Oliveira. Associada a Acanthophora muscoides (Linnaeus) Bory de Saint-Vincent, Amphiroa fragilissima, Bryopsis pennata J.V.Lamouroux, Ceramium spp. e Wrangelia argus (Montagne) Montagne.

Material selecionado - Entre Rios, Subaúma, 25 out. 2010, P.B. Jesus et al. (ALCB 100249-9); Mata de São João, Praia do Forte, 25 set. 2010, P.B. Jesus et al. (ALCB 100251-ᄋ, 100252-Ø, 100258 -Оึ), Imbassaí, 23 out. 2010, P.B. Jesus et al. (ALCB100194-ㅇ, 100246- $\hat{O}$, 100247- $\partial$, 100248- $)$ ); Salvador, Stella Maris, 6 nov. 2010, P.B. Jesus et al. (ALCB 100256- + ); Ilha de Itaparica, Vera Cruz, Mar Grande, 4 dez. 2010, P.B. Jesus et al. (ALCB 100198-ㅇ, 100243-ㅇ, 100244-ð, 100250-Ø), Penha, 5 dez. 2010, P.B. Jesus et al. (ALCB 100245- $\left.{ }^{\Uparrow}\right)$; Uruçuca, Serra Grande, 18 abr. 2011, P.B. Jesus et al. (ALCB 100259-文); Ilhéus, Gravatá, 17 abr. 2011, P.B. Jesus et al. (ALCB 100253, 100254-Ø, 100255-ㅇ); Porto Seguro, Arraial D’Ajuda, Mucugê, 6 nov. 2010, P.B. Jesus et al. (ALCB 100257-ㅇ). 

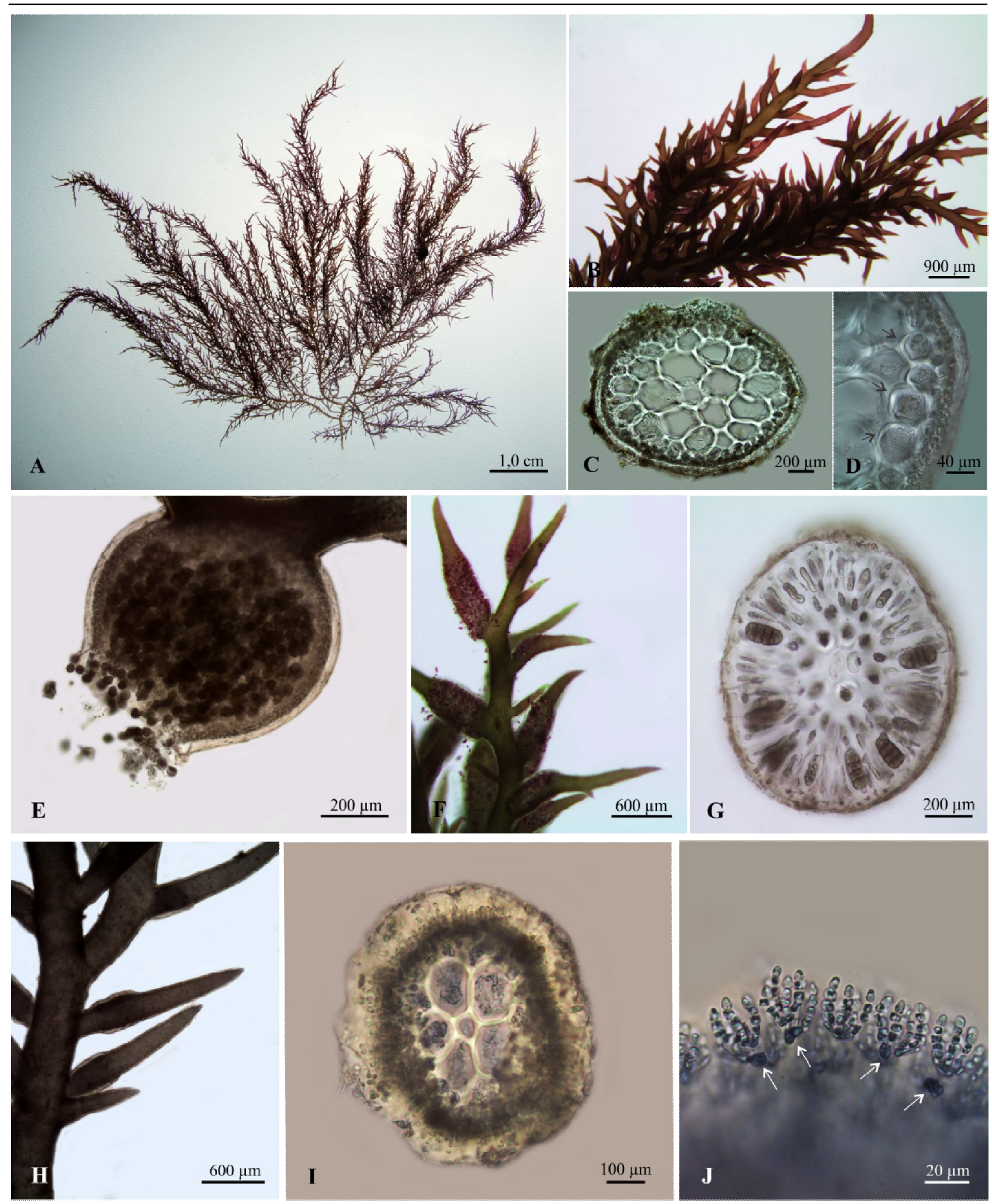

Figura 15. Hypnea valentiae (ALCB 100194, 100246, 100247, 100249, 100253-100255): A- hábito de um gametófito feminino; B- detalhe da região apical do talo coberta por inúmeros râmulos direcionados para cima; C- corte transversal na base do eixo principal; D- células corticais em corte transversal, notar espessamentos lenticulares nas células medulares (setas); E- cistocarpo em detalhe; F- râmulos férteis com a região basal alargada pelo desenvolvimento dos tetrasporângios; G- corte transversal de um râmulo fértil mostrando a disposição dos tetrasporângios na região cortical; H- râmulos férteis com a região basal alargada pelo desenvolvimento dos espermatângios; I- corte transversal de um râmulo fértil mostrando a disposição dos espermatângios na região cortical; J- detalhe dos espermatângios formados de maneira concatenada a partir da célula mãe (setas) derivada de uma célula cortical. 
Hypnea valentiae se distingue das outras espécies do litoral baiano pelo tamanho, geralmente maior, pela ramificação em ângulos retos ou quase retos e pelos longos ramos laterais, o que confere um aspecto laxo à sua fronde (Tabela 1). Os râmulos geralmente direcionados para cima, cobrindo completamente o eixo principal e os ramos laterais constituem outra particularidade desta espécie. $\mathrm{O}$ material analisado concorda com a descrição e ilustração originais apresentadas por Turner (1809, como Fucus valentiae Turner) e com as características apontadas por Dawson (1961), Abbott \& Hollemberg (1976), Mshigeni (1978), Schenkman (1986), Womersley (1994), Abbott (1999) e Prud'homme van Reine \& Trono Jr (2001).

Agardh (1852), Børgesen (1943) Schneider \& Searles (1991) e Mshigeni \& Chapman (1994) descrevem esta espécie portando râmulos estrelados com três a seis pontas. Apesar disto, nenhum destes autores traz ilustrações que possam auxiliar o reconhecimento destes râmulos; apenas Mshigeni \& Chapman, que provavelmente observaram o mesmo material de Agardh, trazem informações mais detalhadas. Segundo estes autores, os râmulos estrelados de $H$. valentiae são grandes e firmemente aderidos ao talo, diferente dos râmulos peltados de $H$. cornuta, espécie com a qual é frequentemente confundida.

Mshigeni \& Chapman (1994) afirmam ainda que Hypnea valentiae é distinta de $H$. cornuta pela presença de râmulos horizontais, subulados, pequenos e geralmente simples, como foi exposto em sua descrição original por Turner (1809). Segundo Abbott (1999), grande parte dos espécimes analisados de

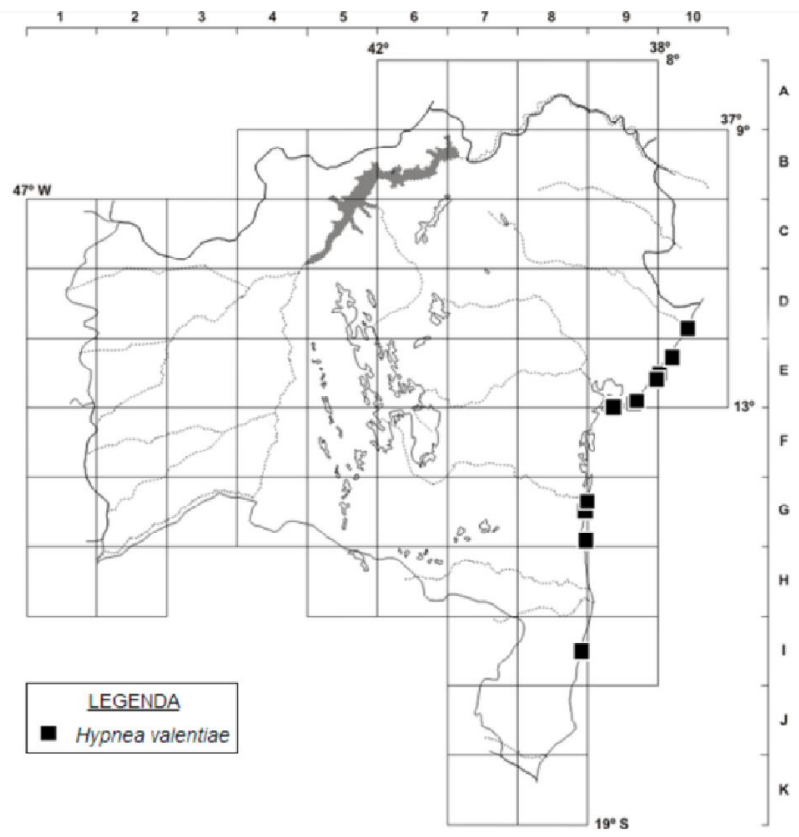

Figura 16. Mapa de distribuição de Hypnea valentiae no litoral do estado da Bahia.
H. valentiae do Havaí apresentam apenas râmulos simples e espinescentes, considerando a presença de râmulos estrelados uma característica pouco confiável para H. valentiae. Assim como Schenkman (1986) observou para os exemplares do estado de São Paulo, nenhum dos espécimes examinados de $H$. valentiae do litoral da Bahia apresentou râmulos estrelados.

Praticamente não há relatos na literatura no que diz respeito à estrutura interna de Hypnea valentiae. Schenkman (1986) afirmou apenas que, em corte transversal, o talo pode apresentar uma célula axial pequena e cinco a sete periaxiais grandes; Prud'homme van Reine \& Trono Jr (2001) apontam de seis a oito periaxiais grandes com espessamento lenticular em suas paredes, mas não traz medidas nem ilustrações das mesmas. Os exemplares baianos apresentam uma célula axial de contorno estrelado e quatro a seis periaxiais grandes com contorno irregular e, geralmente apresentam espessamentos lenticulares nas paredes das células periaxiais e medulares.

\section{CONSIDERAÇõES FINAIS}

Como ressaltado por Yamagishi \& Masuda (2000), a maioria das características atualmente empregadas na taxonomia do gênero Hypnea pode variar dependendo do hábitat. $\mathrm{O}$ sistema de fixação, tamanho, textura e a cor das algas recém-coletadas podem variar bastante por estarem fortemente associados ao local onde as espécies são encontradas. Assim, os aspectos morfoanatômicos que contribuíram para a distinção das espécies estudadas no litoral do estado da Bahia foram: tipo de ápice, modo de fixação ao substrato, tipo de inserção dos ramos laterais nos eixos, forma e disposição dos râmulos nos ramos e eixos, tamanho e forma das células periaxiais e, disposição dos tetrasporângios e espermatângios nos râmulos férteis. Ainda assim, é necessário um estudo minucioso de todas estas características em conjunto para que se possa realizar uma identificação segura e precisa.

\section{Agradecimentos}

Ao Programa de Pós-Graduação em Botânica da Universidade Estadual de Feira de Santana e à FAPESB (PRONEM - T.O.PNE 0020/2011), pelo financiamento das coletas; ao Laboratório de Algas Marinhas do Instituto de Biologia da Universidade Federal da Bahia, pela disponibilização da infraestrutura; e aos curadores dos herbários consultados pela disponibilização do acesso ao material. Este trabalho é parte da dissertação de mestrado da primeira autora, realizada com bolsa da CAPES. 
Tabela 1. Comparação das características morfológicas, anatômicas e reprodutivas das espécies de Hypnea (- = dados não disponíveis).

\begin{tabular}{|c|c|c|c|c|c|c|c|c|}
\hline & H. cenomyce & H. cervicornis & H. cornuta & H. musciformis & H. nigrescens & H. platyclada & H. spinella & H. valentiae \\
\hline Hábitat & $\begin{array}{l}\text { epífita ou } \\
\text { epilítica no } \\
\text { mediolitoral e } \\
\text { infralitoral }\end{array}$ & $\begin{array}{l}\text { epífita ou } \\
\text { epilítica } \\
\text { no } \\
\text { mediolitoral e } \\
\text { infralitoral }\end{array}$ & $\begin{array}{l}\text { epilítica no } \\
\text { mediolitoral }\end{array}$ & $\begin{array}{l}\text { epífita ou } \\
\text { epilítica no } \\
\text { mediolitoral e } \\
\text { infralitoral }\end{array}$ & $\begin{array}{l}\text { epífita ou } \\
\text { epilítica no } \\
\text { mediolitoral }\end{array}$ & $\begin{array}{l}\text { epífita no } \\
\text { mediolitoral }\end{array}$ & $\begin{array}{l}\text { epífita ou } \\
\text { epilítica no } \\
\text { mediolitoral e } \\
\text { infralitoral }\end{array}$ & $\begin{array}{l}\text { epífita ou } \\
\text { epilítica no } \\
\text { mediolitoral e } \\
\text { infralitoral }\end{array}$ \\
\hline Hábito & $\begin{array}{l}\text { base prostrada } \\
\text { e ramos eretos, } \\
\text { formando tufos }\end{array}$ & ereto & ereto & ereto & $\begin{array}{l}\text { ereto, } \\
\text { formando tufos }\end{array}$ & prostrado & $\begin{array}{l}\text { prostrado, } \\
\text { formando tufos }\end{array}$ & ereto \\
\hline $\begin{array}{l}\text { Tamanho } \\
\text { (altura -cm) }\end{array}$ & $0,5-1$ & $4-24$ & $9-15$ & $2-15$ & $2,5-8$ & $1-3$ & $0,5-3$ & $4,5-23$ \\
\hline Cor & $\begin{array}{l}\text { róseo- } \\
\text { avermelhada }\end{array}$ & $\begin{array}{l}\text { róseo- } \\
\text { esverdeada, } \\
\text { amarela ou } \\
\text { amarronzada }\end{array}$ & $\begin{array}{l}\text { amarela } \\
\text { amarronzada }\end{array}$ & $\begin{array}{l}\text { vinácea, } \\
\text { esverdeada ou } \\
\text { amarronzada }\end{array}$ & $\begin{array}{l}\text { verde, negro- } \\
\text { esverdeada ou } \\
\text { vinácea }\end{array}$ & rósea & $\begin{array}{l}\text { róseo- } \\
\text { esverdeada a } \\
\text { róseo-vinácea }\end{array}$ & $\begin{array}{l}\text { róseo-vinácea } \\
\text { ou amarrozada }\end{array}$ \\
\hline Textura & membranácea & $\begin{array}{l}\text { membranácea } \\
\text { a cartilaginosa }\end{array}$ & cartilaginosa & $\begin{array}{l}\text { membranácea a } \\
\text { cartilaginosa }\end{array}$ & cartilaginosa & cartilaginosa & $\begin{array}{l}\text { membranácea } \\
\text { a cartilaginosa }\end{array}$ & $\begin{array}{l}\text { membranácea a } \\
\text { cartilaginosa }\end{array}$ \\
\hline $\begin{array}{l}\text { Tipo de } \\
\text { fixação ao } \\
\text { substrato }\end{array}$ & $\begin{array}{l}\text { discos de } \\
\text { fixação na base } \\
\text { estolonífera e } \\
\text { nos ramos }\end{array}$ & $\begin{array}{l}\text { disco de } \\
\text { fixação } \\
\text { primário ou } \\
\text { ramos rizoidais } \\
\text { com discos de } \\
\text { fixação } \\
\text { acessórios }\end{array}$ & $\begin{array}{l}\text { ramos rizoidais } \\
\text { e discos de } \\
\text { fixação }\end{array}$ & $\begin{array}{l}\text { disco de fixação } \\
\text { primário, } \\
\text { gavinhas ou } \\
\text { estolão }\end{array}$ & ramos rizoidais & $\begin{array}{l}\text { porção } \\
\text { estolonífera e } \\
\text { discos de } \\
\text { fixação } \\
\text { secundários }\end{array}$ & $\begin{array}{l}\text { discos de } \\
\text { fixação }\end{array}$ & $\begin{array}{l}\text { disco de } \\
\text { fixação único } \\
\text { ou ramos } \\
\text { rizoidais }\end{array}$ \\
\hline Anastomose & ausente & rara & ausente & ausente & ausente & presente & presente & ausente \\
\hline $\begin{array}{l}\text { Forma do eixo } \\
\text { principal }\end{array}$ & cilíndrico & cilíndrico & cilíndrico & cilíndrico & cilíndrico & $\begin{array}{l}\text { achatado,com } \\
\text { pedúnculo } \\
\text { cilíndrico }\end{array}$ & cilíndrico & cilíndrico \\
\hline $\begin{array}{l}\text { Largura do } \\
\text { eixo principal } \\
\text { (base - } \mu \mathrm{m})\end{array}$ & $83-159$ & $529-1.036$ & $937-1.350$ & $342-690$ & $447-650$ & $108-2.046$ & $393-1.144$ & $628-721$ \\
\hline $\begin{array}{l}\text { Inserção dos } \\
\text { ramos laterais } \\
\text { no eixo } \\
\text { principal }\end{array}$ & irregular & $\begin{array}{l}\text { dicotômica a } \\
\text { subdicotômica }\end{array}$ & $\begin{array}{l}\text { alterna a } \\
\text { irregular }\end{array}$ & irregular & irregular & irregular & irregular & $\begin{array}{l}\text { irregular a } \\
\text { alterna }\end{array}$ \\
\hline $\begin{array}{l}\text { Forma dos } \\
\text { râmulos }\end{array}$ & espinescente & espinescente & $\begin{array}{l}\text { espinescente } \\
\text { ou estrelada }\end{array}$ & espinescente & subulada & espinescente & espinescente & $\begin{array}{l}\text { subulado ou } \\
\text { espinescente }\end{array}$ \\
\hline $\begin{array}{l}\text { Inserção dos } \\
\text { râmulos }\end{array}$ & irregular & $\begin{array}{l}\text { irregular na } \\
\text { base e alterna } \\
\text { com tendência } \\
\text { a dística no } \\
\text { ápice }\end{array}$ & $\begin{array}{l}\text { alterna a } \\
\text { dística }\end{array}$ & irregular & $\begin{array}{l}\text { irregular com } \\
\text { tendência a } \\
\text { espiralada, } \\
\text { direcionados } \\
\text { para cima. }\end{array}$ & irregular & $\begin{array}{l}\text { irregular a } \\
\text { alterna }\end{array}$ & $\begin{array}{l}\text { espiralada ou } \\
\text { radial, } \\
\text { direcionados } \\
\text { para cima }\end{array}$ \\
\hline $\begin{array}{l}\text { Forma do } \\
\text { ápice }\end{array}$ & $\begin{array}{l}\text { agudo ou } \\
\text { arredondado }\end{array}$ & $\begin{array}{l}\text { agudo ou } \\
\text { bifurcado }\end{array}$ & agudo & gavinha & $\begin{array}{l}\text { agudo, reto, } \\
\text { recurvado ou } \\
\text { em forma de } \\
\text { gancho não } \\
\text { dilatado }\end{array}$ & agudo & $\begin{array}{l}\text { agudo, reto, } \\
\text { recurvado ou } \\
\text { bifurcado }\end{array}$ & $\begin{array}{l}\text { ereto, agudo, } \\
\text { recurvado ou } \\
\text { em forma de } \\
\text { gancho não } \\
\text { dilatado }\end{array}$ \\
\hline Célula axial & pequena & pequena & pequena & grande & grande & pequena & pequena & pequena \\
\hline $\begin{array}{l}\text { Número e } \\
\text { forma das } \\
\text { células } \\
\text { periaxiais }\end{array}$ & 5 ou 6 ovais & $\begin{array}{l}4 \text { ou } 6 \text { ovais- } \\
\text { triangulares }\end{array}$ & 5 ou 6 ovais & 6-8 irregulares & 5-7 irregulares & $\begin{array}{l}5 \text { ou } 6 \\
\text { arredondadas }\end{array}$ & $\begin{array}{l}5 \text { ou } 6 \text { ovais- } \\
\text { triangulares }\end{array}$ & $\begin{array}{l}4-6 \\
\text { arredondadas } \\
\text { ou irregulares }\end{array}$ \\
\hline $\begin{array}{l}\text { Células } \\
\text { medulares }\end{array}$ & $\begin{array}{l}\text { ausentes ou em } \\
\text { uma camada }\end{array}$ & $\begin{array}{l}1 \text { ou } 2 \text { camadas } \\
\text { arredondadas }\end{array}$ & $\begin{array}{l}2 \text { ou } 3 \text { camadas } \\
\text { arredondadas }\end{array}$ & $\begin{array}{l}2 \text { ou } 3 \text { camadas } \\
\text { irregulares ou } \\
\text { arredondadas }\end{array}$ & $\begin{array}{l}2 \text { camadas } \\
\text { oval- } \\
\text { triangulares a } \\
\text { oval- } \\
\text { quadráticas }\end{array}$ & $\begin{array}{l}2 \text { camadas } \\
\text { ovais a } \\
\text { circulares }\end{array}$ & $\begin{array}{l}1 \text { ou } 2 \text { camadas } \\
\text { arredondadas }\end{array}$ & $\begin{array}{l}\text { (2) } 3 \text { camadas } \\
\text { arredondadas }\end{array}$ \\
\hline $\begin{array}{l}\text { Espessamento } \\
\text { lenticular }\end{array}$ & presente & presente & presente & presente & raro & presente & presente & presente \\
\hline $\begin{array}{l}\text { Forma das } \\
\text { células } \\
\text { corticais em } \\
\text { vista } \\
\text { superficial }\end{array}$ & $\begin{array}{l}\text { isodiamétricas } \\
\text { de mesmo } \\
\text { tamanho }\end{array}$ & $\begin{array}{l}\text { isodiamétricas } \\
\text { de mesmo } \\
\text { tamanho }\end{array}$ & $\begin{array}{l}\text { isodiamétricas } \\
\text { de mesmo } \\
\text { tamanho }\end{array}$ & $\begin{array}{l}\text { isodiamétricas } \\
\text { de mesmo } \\
\text { tamanho }\end{array}$ & $\begin{array}{l}\text { isodiamétricas } \\
\text { de mesmo } \\
\text { tamanho }\end{array}$ & $\begin{array}{l}\text { isodiamétricas } \\
\text { de tamanho } \\
\text { desigual }\end{array}$ & $\begin{array}{l}\text { isodiamétricas } \\
\text { de mesmo } \\
\text { tamanho }\end{array}$ & $\begin{array}{l}\text { isodiamétricas } \\
\text { de mesmo } \\
\text { tamanho }\end{array}$ \\
\hline $\begin{array}{l}\text { Disposição } \\
\text { dos soros } \\
\text { tetrasporan- } \\
\text { giados }\end{array}$ & $\begin{array}{l}\text { mediano ou } \\
\text { apical, } \\
\text { imersos na } \\
\text { região medular } \\
\text { dos ramos }\end{array}$ & $\begin{array}{l}\text { basal ou } \\
\text { mediano, } \\
\text { circundando os } \\
\text { râmulos }\end{array}$ & $\begin{array}{l}\text { basal ou } \\
\text { mediano, } \\
\text { circundando os } \\
\text { râmulos }\end{array}$ & $\begin{array}{l}\text { basal ou } \\
\text { mediano, } \\
\text { circundando os } \\
\text { râmulos }\end{array}$ & $\begin{array}{l}\text { basal ou } \\
\text { mediano, } \\
\text { circundando os } \\
\text { râmulos } \\
\text { completa ou } \\
\text { incompletamen } \\
\text { te }\end{array}$ & unilateral & $\begin{array}{l}\text { apical, basal ou } \\
\text { mediano, } \\
\text { circundando os } \\
\text { râmulos }\end{array}$ & $\begin{array}{l}\text { basal ou } \\
\text { mediano, } \\
\text { circundando os } \\
\text { râmulos }\end{array}$ \\
\hline $\begin{array}{l}\text { Disposição } \\
\text { dos soros de } \\
\text { espermatângi } \\
\text { os }\end{array}$ & - & $\begin{array}{l}\text { basal ou } \\
\text { mediano, } \\
\text { circundando os } \\
\text { râmulos }\end{array}$ & - & - & $\begin{array}{l}\text { basal ou } \\
\text { mediano, } \\
\text { circundando os } \\
\text { râmulos } \\
\text { completa ou } \\
\text { incompleta- } \\
\text { mente }\end{array}$ & unilateral & - & $\begin{array}{l}\text { basal ou } \\
\text { mediano, } \\
\text { circundando os } \\
\text { râmulos - }\end{array}$ \\
\hline
\end{tabular}




\section{REFERÊNCIAS}

Abbott, I.A. 1999. Marine Red Algae of the Hawaiian Islands. Bishop Museum Press, Honolulu.

Abbott, I.A. \& Hollemberg, G. 1976. Marine Algae of California. Stanford University Press, Stanford.

Agardh, J.G. 1852. Species Genera et Ordines Algarum. Vol. 2, part.2. C.W.K. Gleerup, Lund.

Amado-Filho, G. 1991. Algas Marinhas Bentônicas do Litoral de Saquarema a Itacoatira (RJ). Dissertação de Mestrado. Universidade Federal do Rio de Janeiro.Bangmei, X. \& Yongqiang, W. 1997. Some species of the genus Hypnea (Gigartinales, Rhodophyta) from China. In: I.A. Abbott (ed.), Taxonomy of Economic Seaweeds. Vol. 6. California Sea Grant College, University of California, La Jolla, p.193-206.

Børgesen, F. 1943. Some marine algae from Mauritius. III. Rhodophyceae. Part 2. Gelidiales, Cryptonemiales, Gigartinales. Det Kongelige Danske Videnskabernes Selskab. Biologiske Meddelelser 19(1): 1-85.

Cecere, E.; Petrocelli, A. \& Verlaque, M. 2004. Morphology and vegetative reproduction of the introduced species Hypnea cornuta (Rhodophyta, Gigartinales) in the Mar Piccolo of Tarant (Italy), Mediterranean Sea. Botanica Marina 47: 381388.

Cecere, E., Petrocelli, A. \& Verlaque, M. 2011. Vegetative reproduction by multicellular propagules in Rhodophyta: an overview. Marine Ecology 32(4): 419-437.

Chiang, Y.M. 1997. Species de Hypnea Lamouroux (Gigartinales, Rhodophyta) from Taiwan. In: I.A. Abbott (ed.), Taxonomy of Economic Seaweeds. Vol. 6. California Sea Grant College, University of California, La Jolla, p. 163-177.

Collins, F.S. \& Harvey, A.B. 1917. The algae of Bermuda. Proceedings of the American Academy of Arts and Sciences 53: $1-195$.

Dawes, C.J. \& Mathieson, A.C. 2008. The Seaweeds of Florida. University Press of Florida, Florida.

Dawson, E.Y. 1961. Marine red algae of the Pacific Mexico. Part 4. Gigartinales. Pacific Naturalist 2: 191-343.

De Toni, G.B. 1897. Sylloge Algarum Omnium Hucusque Cognitarum. Vol. IV: Florideae. Sectio II. Publicado pelo autor, Padua.

Guimarães, S.M.P.B. 2006. Checklist of Rhodophyta from the State of Espírito Santo. Boletim do Instituto de Botânica de São Paulo 17: 143-194.

Guiry, M.D. \& Guiry, G.M. 2013. AlgaeBase. World-wide electronic publication. National University of Ireland, Galway. Disponível em <http://www.algaebase.org>; acesso em 7 abr. 2013.

Haroun, R.J. \& Prud'Homme van Reine, W.F. 1993. A biogeographical study of Laurencia and Hypnea species of the Macaronesian region. Courier Forschungsinstitut Senckenberg 159: $119-125$.

Jesus, P.B. \& Nunes, J.M.C. 2012. Estudos morfológicos e taxonômicos em Hypnea cornuta (Kützing) J. Agardh (Gigartinales, Rhodophyta) no litoral da Bahia, Brasil. Acta Botanica Brasilica 26(4): 973-978.
Jesus, P.B.; Guimarães, S.M.P.B. \& Nunes, J.M.C. 2013. Hypnea platyclada, a new species of red alga (Rhodophyta, Cystocloniaceae) from Brazil. Phytotaxa 85(1): 26-34.

Joly, A.B.; Ferreira, M.M.; Pinheiro-Vieira, F. \& YoneshigueBraga, Y. 1968. Additions to the American South Atlantic Marine Algae. I. Arquivos da Estação de Biologia Marinha da Universidade Federal do Ceará 8(2): 177-181.

Kützing, F.T. 1868. Tabulae phycologicae; Oder, Abbildungen der Tange. Vol. 18. Publicado pelo autor, Nordhausen.

Lamouroux, J.V. F. 1813. Essai sur les genres de la famille des thalassiophytes. Annales Du Muséum d'Histoire Naturelle 20: 21-47, 115-139, 267-293.

Lawson, G.W. \& John, D.M. 1987. The marine algae and coastal environment of tropical West Africa. Beiheft. Nova Hedwigia 93: $1-415$.

Lucio, A.M. 2006. El Género Hypnea (Rhodophyta) en las Costas del Océano Atlántico. Tese de Doutorado. Universidad Complutense de Madrid.

Masuda, M.; Yamagishi, Y.; Chiang, Y.-M.; Lewmanomont, K. \& Xia, B.M. 1997. Overview of Hypnea (Rhodophyta, Hypneaceae). In: I.A. Abbott (ed.), Taxonomy of Economic Seaweeds. Vol. 6. California Sea Grant College, University of California, La Jolla, p. 127-133.

Mshigeni, K.E. 1978. The biology and ecology of benthic marine algae with special reference to Hypnea (Rhodophyta, Gigartinales): a review of the literature. Bibliotheca Phycologica 37: 1-168.

Mshigeni, K.E. \& Chapman, D.J. 1994. Hypnea (Gigartinales, Rhodophyta). In: I. Akatsuka (ed.), Biology of Economic Algae. SPB Academic Publishing, The Hague, p. 245-281.

Nunes, J.M.C. 2005. Rodofíceas Marinhas Bentônicas do Estado da Bahia, Brasil. Tese de Doutorado. Universidade de São Paulo.

Nunes, J.M.C. 2010. Taxonomia morfológica: metodologia de trabalho. In: A.G. Pedrini, (org.), Macroalgas: uma introdução à sua taxonomia. Vol. 1. Technical Books, Rio de Janeiro, p. $54-70$.

Nunes, J.M.C.; Moura, C.W.N.; Creed, M.; Fujii, M.T.; Cassano, V.; Barros-Barreto, M.B.B.; Pereira, S.M.B.; Khader, S.; Necchi Jr, O.; Oliveira, M.C.; Henriques, M.C.; Oliveira-Carvalho, M.F. \& Guimarães, S.M.P.B. 2013. Rhodophyceae. In: Lista de Espécies da Flora do Brasil. Jardim Botânico do Rio de Janeiro. Disponível em: http://floradobrasil.jbrj.gov.br/jabot/floradobrasil/FB100399; acesso em 7 abr. 2013.

Ogawa, H. \& Lewmanomont, K. 1981. Economic seaweeds of Thailand. I. The genus Hypnea in the Vicinity of Si Racha, Chonburi Province. Kasetsart University Fisheries Research Bulletin 12: 1-14.

Price, I.R. \& Scott, F.J. 1992. The Turf Algal Flora of the Great Barrier Reef. Part I. Rhodophyta. James Cook University, Townsville.

Prud'Homme van Reine, W.F. \& Trono Jr, G.C. (eds) 2001. Cryptogams: Algae. Plant Resources of Southeast Asia 15: 1318.

Reis-Santos, R.P. 1990. Flora Algal da Lagoa de Araruama, Rio de Janeiro. Dissertação de Mestrado. Universidade Federal do Rio de Janeiro. 
Schenkman, R.P.F. 1980. Biomassa, Crescimento e Ficocolóide de Hypnea Musciformis (Rhodophyta) no Litoral do Estado de São Paulo, Brasil. Dissertação de Mestrado. Universidade de São Paulo.

Schenkman, R.P.F. 1986. Cultura de Hypnea (Rhodophyta) In Vitro como Subsídio para Estudos Morfológicos, Reprodutivos e Taxonômicos. Tese de Doutorado. Universidade de São Paulo.

Schneider, C.W. \& Searles, R.B. 1991. Seaweeds of the Southeastern United States. Cape Hatteras to Cape Canaveral. Duke University Press, Durham.

Silva, P.C.; Basson, P.W. \& Moe, R.L. 1996. Catalogue of the marine algae of the Indian Ocean. University of California Publication. Botany 79: 1-1259.

Tanaka, T. 1941. The genus Hypnea from Japan. Scientific Papers of the Institute of Algological Research, Faculty of Science, Hokkaido Imperial University 2: 227-250.

Taylor, W.R. 1960. Marine Algae of the Eastern Tropical and Subtropical Coasts of the Americas. The University of Michigan Press, Ann Arbor.

Turner, D. 1809. Fuci. Vol II. John \& Arthur Arch, Cornhill.

Womersley, H.B.S, 1994. The Marine Benthic Flora of Southern Australia. Part III-A. Bangiophyceae and Florideophyceae (Acrochaetiales, Nemaliales, Gelidiales, Hildenbrandiales and Gigartinales sensu lato). Australian Biological Resources Study, Camberra.

Wynne, M.J. 1995. Benthic marine algae from the Seychelles collected during the R/V Te Vega Indian Ocean expedition. Contributions of the University of Michigan Herbarium 20(2): 261-346.
Wynne, M.J. 1998. A checklist of the benthic marine algae of the tropical and subtropical western Atlantic: first revision. Beiheft. Nova Hedwigia 16: 1-155.

Wynne, M.J. 2005. A checklist of benthic marine algae of the tropical and subtropical western Atlantic: second revision. Beiheft. Nova Hedwigia 129: 1-152.

Wynne, M.J. 2011. A checklist of the benthic marine algae of the tropical and subtropical Western Atlantic: third revision. Beiheft. Nova Hedwigia 140: 1-160.

Yamagishi, Y. \& Masuda, M. 1997. Species de Hypnea from Japan. In: I.A. Abbott (ed.), Taxonomy of Economic Seaweeds. Vol. 6. California Sea Grant College, University of California, La Jolla. p. 135-162.

Yamagishi, Y. \& Masuda, M. 2000. A taxonomic revision of the Hypnea charoides-valentiae complex (Rhodophyta, Gigartinales) in Japan, with a description of Hypnea flexicaulis sp. nov. Phycological Research 48: 27-35.

Yoneshigue-Valentin, Y. 1985. Taxonomie et Ecologie des Algues Marines dans la Region de Cabo Frio (Rio de Janeiro, Bresil). Tese de Doutorado. Faculté dês Sciences de Lumin. L'Universite D'aix, Marseille.

Yoneshigue-Valentin, Y.; Loivos, A.M.; Silva, R.C.C. \& Fernandes, D.R.P. 2008. Contribuição ao conhecimento e preservação das algas multicelulares bentônicas do Costão dos Cavaleiros - Macaé, estado do Rio de Janeiro. Iheringia série Botânica 63: 129-134. 